\title{
The Formation of Consumer Inflation Expectations: New Evidence From Japan's Deflation Experience
}

\author{
Jess Diamond ${ }^{*}$ \\ diamond@hosei.ac.jp \\ Kota Watanabe \\ watanabe.kota@canon-igs.org \\ Tsutomu Watanabe \\ watanabe@e.u-tokyo.ac.jp
}

No.19-E-13

Bank of Japan

Department of Economics, Hosei University

** Canon Institute for Global Studies and University of Tokyo

"**aduate School of Economics, University of Tokyo

Papers in the Bank of Japan Working Paper Series are circulated in order to stimulate discussion and comments. Views expressed are those of authors and do not necessarily reflect those of the Bank.

If you have any comment or question on the working paper series, please contact each author. When making a copy or reproduction of the content for commercial purposes, please contact the Public Relations Department (post.prd8@boj.or.jp) at the Bank in advance to request permission. When making a copy or reproduction, the source, Bank of Japan Working Paper Series, should explicitly be credited. 


\title{
The Formation of Consumer Inflation Expectations: New Evidence From Japan's Deflation Experience
}

\author{
Jess Diamond $^{\dagger} \quad$ Kota Watanabe W $^{\ddagger} \quad$ Tsutomu Watanabe ${ }^{\S}$
}

August 2019

\begin{abstract}
Using a new micro-level dataset we investigate the relationship between the inflation experience and inflation expectations of households in Japan. We focus on the period after 1995, when Japan began its era of deflation. Our key findings are fourfold. Firstly, we find that inflation expectations tend to increase with age. Secondly, we find that measured inflation rates of items purchased also increase with age. However, we find that age and inflation expectations continue to have a positive correlation even after controlling for the household-level rate of inflation. Further analysis suggests that the positive correlation between age and inflation expectations is driven to a significant degree by the correlation between cohort and inflation expectations, which we interpret to represent the effect of historical inflation experience on expectations of future inflation rates.
\end{abstract}

Keywords: Inflation Expectations, Deflation, Monetary Policy, Household Level Inflation Data, Japan

\footnotetext{
${ }^{\dagger}$ Department of Economics, Hosei University. E-mail: diamond@hosei.ac.jp

${ }^{\ddagger}$ Canon Institute for Global Studies (GIGS) and University of Tokyo. E-mail: watanabe.kota@canonigs.org

${ }^{\S}$ Graduate School of Economics, University of Tokyo. Email: watanabe@e.u-tokyo.ac.jp

"We thank Anil Kashyap, Nobuhiro Kiyotaki, Edward Lazear, James Poterba, Stephen Redding, David Weinstein and participants of the 2016 NBER Japan Project Meeting in Tokyo, Japan. We also thank participants of the 8th CARF-BOJ Joint Conference on Issues Concerning Recent Inflation Dynamics: The Experience of Japan. This research forms part of the project on "Central Bank Communication Design" funded by a JSPS Grant-in-Aid for Scientific Research (No. 18H05217).
} 


\section{Introduction}

Since at least the time of Keynes (1936), economic agents' expectations of future inflation rates have played a pivotal role in macroeconomics. Woodford (2003) describes the central importance of inflation expectations to modern macroeconomic models due to the intertemporal nature of economic problems, while Sargent (1982) and Blinder (2000) highlight the dependence of monetary policy on these expectations. However, despite the important role of inflation expectations, their formal inclusion in macroeconomic models is usually ad-hoc, with little empirical justification.

This study takes the position that understanding the underlying drivers of inflation expectations is of great importance and we focus on the case of Japan. The formation of inflation expectations in Japan is an important topic of study because of the many lessons it potentially holds for other advanced economies. Japan has experienced deflation since the mid-1990s. Previous studies on Japan's deflation, including Krugman (1998), Eggertsson and Woodford (2003), Svensson (2000), Jung et al. (2005), Ahearne et al. (2002), and Ito and Mishkin (2006) all argue that the key to escape from deflation is to raise inflation expectations, thereby lowering real interest rates.

This prescription is shared by the Japanese government and the Japanese central bank, which raised the inflation target in January 2013 from 1 percent to 2 percent and introduced Quantitative and Qualitative Easing (QQE) in April 2013. Governor Haruhiko Kuroda has clearly stated that the main purpose of QQE is to raise inflation expectations. ${ }^{1}$ Although the early stages of QQE witnessed some improvement in inflation expectations, the effect was not long-lasting and after more than five years since the introduction of QQE we are yet to see a significant increase in inflation expectations.

Of particular interest is that a generation of young adults has not altered their inflation expectations and it is argued that this is because this generation has grown up without ever having experienced inflation. How do their expectations differ from those of earlier generations who experienced high levels of inflation in the 1970s and

\footnotetext{
${ }^{1}$ For example, see Kuroda (2014).
} 
even the hyperinflation that immediately followed World War II? How has the young generation's experience of deflation affected their expectations of inflation in the future and what does this imply for other advanced economies experiencing prolonged periods of near-zero inflation or deflation?

The early literature on the formation of expectations was dominated by the theory of adaptive expectations, in which economic agents use past data on a given variable to form expectations of the variable's future values. This approach to the formation of expectations of economic variables, exemplified by Friedman (1957), has far-reaching implications. In their seminal work, Friedman and Schwartz (1963) argued that the experience of the Great Depression had a profound impact on people's beliefs about the capitalist system and its future. This argument is echoed by Cogley and Sargent (2008), who show how large macroeconomic shocks, such as the Great Depression, can leave very long-lasting impressions on people's beliefs and that a significant period of time is required to correct these pessimistic beliefs. Similarly, Giuliano and Spilimbergo (2014) argue that the experience of a recession in early adulthood makes individuals more likely to favor economic redistribution later in life.

A number of studies have investigated the specific question of how past inflation experience affects future inflation expectations. Johannsen (2014) documents that demographic groups exhibiting greater dispersion in experienced inflation rates also exhibit greater dispersion in future expected inflation rates. He shows that this empirical result is consistent with a model of imperfect information in which households' own rates of inflation serve as signals about the aggregate inflation rate of the macroeconomy. Malmendier and Nagel (2016) propose that actual inflation rates experienced in the past play an important role in the formation of individuals' future inflation expectations. Using micro data from the Michigan Survey of Consumers, they estimate an adaptive learning model in the tradition of Marcet and Sargent (1989) with a twist that allows individuals to overweight the inflation data realized in their own lifetimes. They show that differences in experienced inflation rates can predict differences in future inflation 
expectations.

While the notion that economic agents might overweight data that they have personally experienced has only recently been explored in the discussion of inflation expectations, evidence for such behavior has been documented in other areas. For example, Vissing-Jorgensen (2004) reports that during the stock-market boom of the late 1990s young retail investors with little investment experience displayed the highest expectations for future stock returns. In an experimental setting, Smith et al. (1988) find that asset market bubbles and crashes are less likely when subjects have experienced bubbles and crashes in previous trading sessions and Haruvy et al. (2007) find that inexperienced subjects tend to extrapolate recent price movements. These results suggest the use of adaptive expectations, especially among agents with less experience, in forming future expectations. Furthermore, the results of Greenwood and Nagel (2009) suggest that these results may not be limited to the laboratory. They show that during the late 1990s' technology bubble inexperienced mutual fund managers tended to hold the riskiest portfolios and exhibited trend-chasing behavior.

This study seeks to extend the body of research that investigates the effect of personal experience on the formation of future inflation expectations and provides three main contributions. Firstly, we combine micro data of actual purchases made by households with data on their inflation expectations to investigate whether or not inflation expectations reflect actual recent inflation experience. Previous studies have relied on realized inflation data at the macro level and, consequently, ignored the variation in inflation experiences among households. We document significant variation in inflation expectations among age-groups and analyze how this variation is related to actual experienced inflation rates.

One issue with studies that analyze inflation expectations, and particularly those that use data from surveys such as the Michigan Survey of Consumers, including Carroll (2006), Mankiw et al. (2004) and Johannsen (2014), is that consumers are asked about their views on "prices in general," whereas from a theoretical perspective what 
is arguably most important is individuals' expectations of the prices that are likely to affect their behavior - namely the prices of goods that they purchase. In contrast to the Michigan Survey of Consumers, the survey used in this study asks respondents about the prices of goods that they commonly purchase.

A related study that employs micro data of actual purchases using scanners, similar to the data used in this study, is Kaplan and Schulhofer-Wohl (2017). Our realized inflation data exhibit similar key cross-sectional and time series properties to those found in Kaplan and Schulhofer-Wohl (2017). However, in contrast to Kaplan and Schulhofer-Wohl (2017), whose analysis was conducted at the household level and who concluded that almost all variability in household inflation rates comes from variability in household-level prices relative to average prices rather than from variability in aggregate inflation, we focus on the differences across age groups and find that the primary source of heterogeneity in inflation rates is differences in the amounts consumed of goods in the same common basket, which we term the "weight effect." Furthermore, our dataset contains household-level inflation expectations which we are able to connect to household-level inflation rates and test various hypotheses raised in Kaplan and Schulhofer-Wohl (2017). Our central finding here is that realized inflation rates do not explain differences in inflation expectations.

Secondly, we study the example of Japan, a country which, within the lifetimes of many individuals in our dataset, has experienced both hyperinflation following World War II and the deflation of the last two decades. While previous studies suggest that experiences of high inflation rates increase future inflation expectations, there is less research examining how inflation expectations behave in periods of sustained deflation. Benhabib et al. (2001) and Benhabib et al. (2002) argue that in an economy with deflationary expectations, the zero lower bound on nominal interest rates can cause the economy to become stuck in a liquidity trap, with nominal interest rates stuck at zero and expectations of deflation becoming further embedded.

Finally, we explore how central bank communication - particularly inflation target- 
ing - affects inflation expectations. Numerous studies, such as Ahearne et al. (2002), Ito and Mishkin (2006) and Hoshi and Kashyap (2013), argue that monetary policy was an important contributor to Japan's prolonged deflation. From this perspective it becomes important to understand to what extent monetary policy can affect inflation expectations and what the implications for monetary policy are in an environment where deflation has taken root and interest rates have declined below zero.

The remainder of the paper is organized as follows. In section 2 we describe the dataset used and present summary statistics. In section 3 we construct and examine inflation rates and inflation expectations across age and in Section 4 we formally investigate the relationship between inflation expectations and age. Section 5 attempts to separate the effects of age on expectations from the effect of cohort on expectations and Section 6 discusses the implications of our findings. Section 7 investigates the relationship between inflation targeting by the central bank and inflation expectations. Finally, Section 8 concludes. We also provide an appendix containing a translation of the questionnaire used in our inflation expectations survey.

\section{Data and Summary Statistics}

\subsection{Data}

The first part of this study combines three micro-level datasets of the same 13384 individuals. ${ }^{2}$ The first dataset is a panel dataset of consumers' purchase histories. ${ }^{3}$ Respondents scan the barcode of every item they purchase using a portable home scanner and record the quantity purchased, purchase price and purchase channel (i.e. supermarket, convenience store, etc.) of purchased items. Each good is identified by a 13-digit or 8digit Japanese Article Number (JAN) code. We use the purchase data for the three-year period covering 2012-2014, containing a total of more than 48 million transactions.

The second dataset we employ is a dataset of the same individuals containing demo-

\footnotetext{
${ }^{2}$ All three datasets were constructed jointly by the University of Tokyo and Intage, a Japanese market research firm.

${ }^{3}$ The SCI (Nationwide Consumer Panel Survey).
} 
graphic, educational and financial information. ${ }^{4}$ In particular, this dataset allows us to identify each individual's age, gender, level of education and income group.

The third and final source of data that we use is a survey about prices and inflation using the same individuals as above. The survey questions respondents regarding their perceptions of past prices changes, future price changes and their knowledge of economic and financial matters.

\subsection{Descriptive Statistics}

Table 1 presents sample statistics of selected key demographic, educational and financial variables used in this study. In contrast to surveys that ask respondents about their perceptions of the changes in prices generally, the survey employed in this study asked respondents specifically about the prices of goods that they usually buy. Respondents were asked to indicate their inflation expectations in two ways. The first question asked respondents:

What do you think will happen to prices in a year compared to today? (Please select one):

1. Prices will probably rise substantially

2. Prices will probably rise slightly

3. Prices will probably hardly change

4. Prices will probably fall slightly

5. Prices will probably fall substantially

The second question tried to capture the range in which they believed the prices of goods that they usually purchased would change over the next year. In particular it asked:

By what percent do you think prices will change in the next year compared to today? (Please select one):

\footnotetext{
${ }^{4}$ The Intage Profiler Dataset.
} 
1. Prices will probably rise by $10 \%$ or more

2. Prices will probably rise by between $5 \%$ and $10 \%$

3. Prices will probably rise by between $2 \%$ and $5 \%$

4. Prices will probably rise by between $0 \%$ and $2 \%$

5. Prices will probably not change

6. Prices will probably fall by between $0 \%$ and $2 \%$

7. Prices will probably fall by between $2 \%$ and $5 \%$

8. Prices will probably fall by between $5 \%$ and $10 \%$

9. Prices will probably fall by $10 \%$ or more

In order to avoid confusion, an explanation of what exactly was meant by "prices" was provided four questions earlier in the following way:

"By 'prices' we mean the overall prices of items that you purchase, including food, clothing, daily necessities, household electric appliances, automobiles, eating out, travel, utilities, educational expenses, medical expenses, etc."

The responses from these two questions in the 2014 survey are presented in Tables 2 and 3. Fewer than $3 \%$ of respondents expected to experience deflation in the following year. Although $22 \%$ of respondents did not expect any change in the prices of items that they purchase, two-thirds expected inflation of at least $2 \%$, even though the official inflation rate at the time was only $1.5 \%$ and had exceeded this level only once (AugustSeptember 2008) during the previous 16 years. In fact, $9 \%$ of respondents believed that the inflation rate of prices they faced would exceed $10 \%$.

\section{$3 \quad$ Age and Inflation Expectations}

\subsection{Age Profile of Inflation Expectations}

Figure 1 uses the same data as Table 3 to plot the distribution of inflation expectations over age using the responses to the survey in 2014. One can observe that the proportion 
of respondents who believe that prices will increase by at least $5 \%$ increases with age, while the proportion of respondents who believe that there will be deflation or stable prices decreases with age. While approximately $40 \%$ of young respondents believe that they will experience deflation or flat prices during the next year, only $20 \%$ of older respondents believe so. Why should there be such a large difference in the inflation expectations of young people compared to older people?

\subsection{Why Do Older People Expect Higher Inflation?}

One possible reason is that older individuals have higher levels of income than younger individuals and the apparent relationship between age and inflation expectations in Figure 1 simply reflects a correlation between income and inflation expectations. However, Figure 2, which plots the distribution of inflation expectations over annual household income in 2014, shows a very stable distribution of inflation expectations over levels of household income. This suggests that the relationship between age and inflation expectations observed in Figure 1 is not driven by a relationship between income and inflation expectations.

A second possible reason is that people of different ages purchase their goods through different channels and therefore face different inflation rates for the same goods. This difference in experienced inflation rates might explain the observed differences in inflation expectations across age. To investigate this possibility we begin by aggregating the 2012 and 2013 purchase data for 5-year age groups and construct price levels by age group that includes only goods that are common to all age groups' consumption baskets. The price level is calculated as a Törnqvist index (Törnqvist (1936)) with the weight applied to each good set equal to that good's share of the age group's total consumption. The left-hand side panel of Figure 3 presents the results.

Since the dataset collects only scanner data, we cannot observe many of the prices that are needed to construct a household-level consumer price index, such as housing, utilities, durables, clothing, services, etc. The items that are included in our dataset 
(daily necessities) cover approximately 30 percent of the weight of the Japanese Consumer Price Index. While the weight of these items in the consumption basket of households is relatively small, their role in individuals' perceptions of inflation appear to be far larger. Respondents were presented with 17 options and asked how they reached their judgement about whether prices would rise, fall or remain the same over the following year. ${ }^{5}$

In answering this question, more than $61 \%$ of respondents claimed that they based their judgement on what they expected to happen to the prices of items that they purchase daily (option 1) as their most important reason. This was also given as one of the three most important reasons by $82 \%$ of respondents and as one the five most important reasons by $88 \%$ of respondents. In other words, even though respondents were asked about the overall prices of all of their purchases, the vast majority of them claimed that they based their answers to a large degree on what they expected to happen to prices of goods that they purchase of a daily basis, precisely the goods that are captured by our dataset. For this reason and for readability, we will refer to the inflation rate calculated using only the items in our dataset as the "inflation rate," but it should be kept in mind that it is not an inflation rate calculated from a complete basket of consumption goods, such as the CPI.

One can observe that younger households face similar prices, but that the price level begins to rise from the $40-45$ year-old group onwards. This result is consistent with the work of Abe and Shiotani (2014) who used similar data, but for an earlier period (2004-2006). They found that there is little difference in prices faced by those below age 45 , but that prices begin to increase thereafter. On the other hand, this is the opposite pattern to that found by Aguiar and Hurst (2007). In their research of individuals living in the Denver area in 1993-1995, they found that prices paid tend to fall with age.

In order to isolate the effect of price differences from weight differences on the price level across age groups, we calculate an unweighted price index for each age group and plot the results in the right-hand side panel of Figure 3. One can observe that while the

\footnotetext{
${ }^{5}$ Please refer to Question 11 of the appendix for the actual question that respondents were asked.
} 
same pattern of an increase in the price level can be observed from age 40-45 onwards, the unweighted price level falls until age 40-45. This suggests that, on average, older households pay the highest prices for goods in the common basket. The lowest prices are paid by middle-aged households, while younger households also tend to pay higher prices.

From the price levels by age group above, we construct inflation rates by age group and plot the results in Figure 4. As with the price levels constructed in Figure 3, the inflation rates by age group calculate the inflation rate for each age group by aggregating all the purchase data for age group $j$ and first calculating the mean price for each item $n$ for each year $t\left(p_{n j t}\right)$. Then, we construct a Törnqvist index of the gross change in price $\left(\frac{p_{n j 2013}}{p_{n j 212}}\right)$ with the weight applied to each item equal to the average of that item's share in the age group's aggregated consumption basket over the two years, subtract one from this number and multiply the result by 100 to arrive at the inflation rate by age group, which we refer to as the "age-group-level inflation rate" in Figure 4. In addition to this, we also plot the mean and median of household-level inflation rates within each age-group, which we refer to as "age-group mean" and "age-group median" in the figure.

While the levels are different, all three measures convey the same pattern. Firstly, the experienced rate of inflation increases with age until age 55-59. Thereafter, there appears to be a slight decline. Secondly, all age groups experienced deflation, ranging from more than $1 \%$ for the youngest group to approximately $0.4 \%$ for the $55-59$ year-old group. Thus, part of the reason that older individuals expect higher rates of inflation may lie in the fact that they experience higher inflation.

Interestingly, these results follow a similar pattern to that found by Ueno and Namba (2013) when they investigated inflation rate expectations. They found that inflation expectations in Japan tend to increase with age until approximately age 65 and then begin to fall thereafter. Figure 4 suggests that actual experienced inflation rates tend to follow a similar pattern, although the inflection point appears to occur somewhat earlier, around age 60 . 
A third possibility for why inflation expectations vary across age groups is that people of different ages consume different baskets and thus experience different rates of inflation. In order to determine whether the variation in inflation rates across age is driven by variation in inflation rates for the same items or variation in the baskets consumed, we need to decompose the source of variation in inflation rates into its various components. We perform this exercise in the following subsection.

\subsection{Decomposition of the Inflation Rate into Common and Age Group Specific Factors}

In order to understand the variation in our measured inflation rates across age groups, we can decompose the inflation rate for each age group in the following manner:

$$
\begin{aligned}
\ln \left(\pi_{j t}\right) & =\ln \left(\prod_{n=1}^{N_{j t}} \pi_{n j t}^{\omega_{n j t}}\right) \\
& =\sum_{n \in C} \omega_{n j t} \ln \left(\pi_{n j t}\right)+\sum_{n \notin C} \omega_{n j t} \ln \left(\pi_{n j t}\right)
\end{aligned}
$$

where $\pi_{j t}$ is age group $j$ 's inflation rate in period $t, \pi_{n j t}$ is age group $j$ 's inflation rate for item $n$ in period $t$, given by $\pi_{n j t}=\frac{p_{n j t}}{p_{n j t-1}}, \omega_{n j t}=\frac{1}{2} \times\left(\frac{p_{n j t-1} q_{n j t-1}}{\sum_{n=1}^{N_{j t-1}} p_{n j t-1} q_{n j t-1}}+\frac{p_{n j t} q_{n j t}}{\sum_{n=1}^{N_{j t}} p_{n j t} q_{n j t}}\right)$ and $p_{n j t}$ and $q_{n j t}$ represent the price and quantity of item $n$ for age group $j$ in time period t. $C$ refers to the basket of goods that are consumed by all age groups and $N_{j t}$ is the total number of different items consumed by the members of age group $j$ in period $t$. As data on an item for both period $t-1$ and period $t$ are needed to calculate weight $\omega_{n j t}$, all items that appear in only one year are dropped.

Defining $\overline{\omega_{n t}}$ as the weight of item $n$ in the aggregate basket (i.e. using all of the data) and $\overline{\ln \left(\pi_{n t}\right)}$ as the change in the natural logarithm of the price of item $n$ calculated using the aggregated data (i.e. the change in the natural logarithm of the average price of item $n$ in year $t$ using all of the data), we can rewrite Equation (1) as 


$$
\begin{aligned}
\ln \left(\pi_{j t}\right) & =\sum_{n \in C} \omega_{n j t} \ln \left(\pi_{n j t}\right)+\sum_{n \notin C} \omega_{n j t} \ln \left(\pi_{n j t}\right) \\
& \left.=\sum_{n \in C}\left[\overline{\omega_{n t}}+\Delta \omega_{n j t}\right]\left[\overline{\ln \left(\pi_{n t}\right.}\right)+\Delta \ln \left(\pi_{n j t}\right)\right]+\sum_{n \notin C} \omega_{n j t} \ln \left(\pi_{n j t}\right)
\end{aligned}
$$

where $\Delta \omega_{n j t}$ and $\Delta \ln \left(\pi_{n j t}\right)$ are the deviations of $\omega_{n j t}$ and $\ln \left(\pi_{n j t}\right)$ from their aggregate values, so that $\Delta \omega_{n j t} \equiv \omega_{n j t}-\overline{\omega_{n t}}$ and $\left.\Delta \ln \left(\pi_{n j t}\right) \equiv \ln \left(\pi_{n j t}\right)-\overline{\ln \left(\pi_{n t}\right.}\right)$. Expanding Equation (2) gives

$$
\begin{aligned}
\ln \left(\pi_{j t}\right) & \left.=\sum_{n \in C}\left[\overline{\omega_{n t}}+\Delta \omega_{n j t}\right]\left[\overline{\ln \left(\pi_{n t}\right.}\right)+\Delta \ln \left(\pi_{n j t}\right)\right]+\sum_{n \notin C} \omega_{n j t} \ln \left(\pi_{n j t}\right) \\
& \left.\left.=\sum_{n \in C} \overline{\omega_{n t}} \overline{\ln \left(\pi_{n t}\right.}\right)+\sum_{n \in C} \Delta \omega_{n j t} \overline{\ln \left(\pi_{n t}\right.}\right)+\sum_{n \in C} \overline{\omega_{n t}} \Delta \ln \left(\pi_{n j t}\right) \\
& +\sum_{n \in C} \Delta \omega_{n j t} \Delta \ln \left(\pi_{n j t}\right)+\sum_{n \notin C} \omega_{n j t} \ln \left(\pi_{n j t}\right)
\end{aligned}
$$

The first term on the right-hand side is a common term that is the same for all age groups. We refer to it as the "common component" and it is simply the part of the aggregate inflation rate that comes from the common basket (i.e. the log inflation rate for the basket of goods which all age groups consume). The second term captures the variation in the weights applied for each group and we will refer to this term as the "weight effect." The third term captures the variation in the actual inflation rates experienced by each group and we refer to it as the "price effect." The fourth term is a cross term that we refer to as the "weight-price effect" and the final term is the part of each group's inflation rate that comes from goods that are not in the common basket, which we call the "group-specific basket." A breakdown of each age group's inflation rate in to the terms of Equation (3) is presented in Figure 5.

The left-hand side graph performs the decomposition using 5-year intervals. ${ }^{6}$ One

\footnotetext{
${ }^{6}$ When dividing the sample into 5-year age groups, the value of $N_{j t}$ ranges from 50,554 items (for the 25-29 year old group) to 88,232 items (for the 50-54 year old group). The number of households in
} 
can observe that the price and weight-price effects do not vary much across age groups, with the exception being the 65-69 year old group. The largest variation appears to occur in the weight and group-specific basket components. However, we should not read too much into the variation in the group-specific basket component as it is highly dependent on how the age groups are defined. Defining groups more narrowly will reduce the items that are common to all groups and mechanically increase the group-specific basket component. On the other hand, the weight effect appears to persist even if we change the definition of the age groups. For example, the graph on the right-hand side of Figure 5 uses 10-year age groups rather than 5-year age groups (so that the common basket includes more items and the group-specific baskets fewer items). ${ }^{7}$ As one can observe, variation in the group-specific basket component shrinks, but the weight effect continues to display significant variation across age groups. Thus, our results suggest that much of the variation in inflation rates across age groups is due to differences in the amounts bought of goods in the common basket.

This begs the question of exactly which goods are most important in driving the differences in the weight effect across age groups. In Figure 6 we divide all items into nine major types of goods and further decompose the weight effect in the right-hand side frame of Figure 5 into the contribution of each major type of good. The nine major good types are food, snacks and sweets, baby goods, dairy products, non-alcoholic beverages, alcohol and cigarettes, personal grooming products, household goods and health goods.

Figure 6 reveals that the most important major item groups are food and snacks and sweets. These two major item groups alone account for approximately half of the weight effect. Other significant contributors are non-alcoholic beverages and personal grooming products. It is interesting to note here that health goods are not an important source of variation in the weight effect across age.

A second notable result from Figure 6 is that the contribution of almost every major each group ranges from 1067 (for the 65-69 year old group) to 2045 (for the 45-49 year old group).

${ }^{7}$ When dividing the sample into 10-year age groups, the value of $N_{j t}$ ranges from 56,348 items (for the 20-29 year old group) to 117,104 items (for the 50-59 year old group). The number of households in each group ranges from 1393 (for the 20-29 year old group) to 4059 (for the 40-49 year old group). 
product group to the weight effect is increasing with age. This is an interesting result because, by definition, the larger a given age group's group-specific basket is, the smaller will be the weights on the items in the common basket for that age group $\left(\omega_{n j t}\right)$ and hence the smaller will be the deviation of the given group's weight on a specific item from the aggregate expenditure weight on that item $\left(\Delta \omega_{n j t}\right)$. Thus, one might suspect that the result of Figure 6 is a result of younger households' having smaller weights on the common basket. However, measuring the total weight on the common and group-specific baskets by age group reveals that the weight on the common basket actually decreases monotonically with age, from a high of $86.8 \%$ for the 20-29 year old group to a low of $73.7 \%$ for the $60-69$ year old age group. What is driving the growing weight effect with age is the fact that the correlation between the two terms in the weight effect - $\Delta \omega_{n j t}$ and $\overline{\ln \left(\pi_{n t}\right)}$ - becomes larger with age. ${ }^{8}$ This pattern is generally observed even within each major item group. The conclusion that can be drawn from this is that younger households tend to spend relatively more on items with lower average inflation rates, while older households tend to spend relatively more on items with relatively higher inflation rates.

A second key question that arises from this result is "what is the cause of the difference in weights?" Is it a result of different prices faced by different age groups or is it the result of different preferences? The fact that the group-specific basket accounts for between $13.2 \%$ and $26.3 \%$ suggests that indeed preferences vary across age. Figure 7 describes the distributions of 4 major item group price levels and weights in the overall consumption basket within each age group. They show a variety of patterns. In the case of food, age groups facing higher prices also tend to have higher weights. In the case of snacks and sweets and non-alcoholic beverages, the opposite pattern is observed. Groups facing higher prices tend to have smaller weights. Finally, grooming goods do not appear to have any obvious relationship between prices and weights.

If preferences were identical and higher weights were caused by lower prices, then one would expect households to purchase relatively more of the goods for which they

\footnotetext{
${ }^{8}$ Results not reported in this paper.
} 
face relatively lower prices. However, when we analyze the data at the age-group level, by running regressions of $\Delta \omega_{n j t}$ on $\Delta \ln \left(\pi_{n j t}\right)$, we do not find any statistically significant relationships, unlike the case of the relationship between $\Delta \omega_{n j t}$ and $\left.\overline{\ln \left(\pi_{n t}\right)}\right)^{9}$ While not conclusive, this suggests that the weight differences are more a result of differences in preferences rather than prices faced.

\section{The Effect of Experienced Inflation on Inflation Expec- tations}

In this section we seek to investigate whether the variation in experienced inflation rates documented in the previous section can account for the variation observed in inflation expectations. In particular, we investigate whether or not the positive correlation between age and inflation expectations remains after we have controlled for the fact that older individuals experience higher rates of inflation. Our data do not allow us to observe an individual's expected inflation rate directly. We can observe only his expected inflation rate within a given range, as described in Table 3. Thus, we have interval-coded data where our central variable of interest, the expected inflation rate of individual $i$ over following year $\left(y_{i}^{*}\right)$, cannot be observed. All that can be observed is a range in which it falls.

We assume an individual's expected inflation rate for the following year is determined by the individual's age as well as other factors, $\mathbf{x}_{\mathbf{i}}$, so that it can be described in the following manner.

$$
y_{i}^{*}=\operatorname{Age}_{i} \beta+\mathbf{x}_{\mathbf{i}} \gamma+\varepsilon_{i}
$$

where $\varepsilon_{i} \sim N\left(0, \sigma^{2}\right)$. As shown in Amemiya (1973), the parameters of this linear model, namely $(\beta, \gamma)$ and $\sigma$, can be estimated via maximum likelihood in the same way that one would estimate a Tobit model. In particular, the log likelihood function is given by

\footnotetext{
${ }^{9}$ Results not reported in this paper.
} 
the following:

$$
\begin{aligned}
\ln L= & 1\left[y_{i}=9\right] \log \left[\Phi\left(\frac{-0.1-\operatorname{Age}_{i} \beta-\mathbf{x}_{\mathbf{i}} \gamma}{\sigma}\right)\right]+ \\
& 1\left[y_{i}=8\right] \log \left[\Phi\left(\frac{-0.05-\operatorname{Age}_{i} \beta-\mathbf{x}_{\mathbf{i}} \gamma}{\sigma}\right)-\Phi\left(\frac{-0.1-\operatorname{Age}_{i} \beta-\mathbf{x}_{\mathbf{i}} \gamma}{\sigma}\right)\right]+ \\
& \vdots \\
& 1\left[y_{i}=1\right] \log \left[1-\Phi\left(\frac{0.1-\operatorname{Age}_{i} \beta-\mathbf{x}_{\mathbf{i}} \gamma}{\sigma}\right)\right]
\end{aligned}
$$

where $y_{i}=j$ corresponds to the individual's selecting the $j$ th interval from Table 3 for their expected inflation. Our key focus will be on the impact of the individual's age on his inflation expectations. Since, as we documented above, age and experienced inflation are correlated, we will need to control for the individual's experienced rate of inflation. This rate is calculated for each individual separately as a Törnqvist index using only that individual's purchase data. ${ }^{10}$ In particular, we first calculate the mean price for each good for each household for each year using only the data of that household. We use this average as the price faced by household $i$ for good $n$ in year $t\left(p_{\text {nit }}\right)$. We then calculate the gross price change for each good for each household between year $t$ and year $t-1$ (i.e. $\frac{p_{n i t}}{p_{n i t-1}}$ ). Since we need to observe a good in both years, any goods that are purchased by a household in one year but not the other are automatically dropped from that household's sample. To construct the weight applied to each item, we calculate each good's share of the household's total purchases in each year and use the mean share of the two years as the weight, $\omega_{n i t}=\frac{1}{2} \times\left(\frac{p_{n i t-1} q_{n i t-1}}{\sum_{n=1}^{N_{i}} p_{n i t-1} q_{n i t-1}}+\frac{p_{n i t} q_{n i t}}{\sum_{n=1}^{N_{i}} p_{n i t} q_{n i t}}\right)$. The household-specific inflation rate is then given by

$$
\pi_{i t}=100 \times\left\{\left[\prod_{n=1}^{N_{i}}\left(\frac{p_{n i t}}{p_{n i t-1}}\right)^{\omega_{n i t}}\right]-1\right\}
$$

\footnotetext{
${ }^{10}$ More accurately, we measure the household's inflation rate since our dataset includes items purchased for the entire household and not only the respondent.
} 
Table 4 summarizes key patterns in the dispersion of household-level inflation rates. We present results for inflation rates calculated as Laspeyres, Fisher and Paasche indices in addition to the Törnqvist index. In their analysis of household-level inflation rates in the U.S., Kaplan and Schulhofer-Wohl (2017) found similar patterns. Compared to their results, the measures of dispersion in Table 4 are slightly smaller. Following Kaplan and Schulhofer-Wohl (2017), we can also measure the standard deviation of and amount of serial correlation in household-level inflation rates. The results are shown in Figures 8 and 9. We find a very similar degree of serial correlation (approximately -0.1) to Kaplan and Schulhofer-Wohl (2017) and come to a similar conclusion that almost all of the variation in household-level inflation rates comes from household heterogeneity and very little comes from variation in the aggregate inflation rate.

The survey capturing individuals' expected inflation rates was conducted in March 2014. Thus the experienced inflation rate calculated using the purchase data corresponds to the inflation rate experienced in the previous year (2013). The results of estimating the interval regression of Equation (5) are reported in columns (1) - (6) of Table 5. One can observe that the coefficient on age is precisely estimated and is always positive, implying that for each additional year of age the average expected rate of inflation over the following year increases by 0.04-0.05 percentage points. This may not appear large at first, but consider that it implies that individuals aged 60 expect, on average, inflation for the following year to be 1.2-1.5 percentage points higher than individuals aged 30, all else equal. The point estimate does not vary much as we add control variables to the model. The positive correlation between age and expected inflation appears to be robust, even controlling for factors such as experienced inflation, income, education and information.

A second interesting result is that, even though it is always positive and the value does not vary greatly from model to model, the estimated coefficient on the household inflation rate is never statistically significant. This suggests that, once we control for age, the household's experienced inflation rate over the previous year has no effect on the 
individual's expected inflation rate for the following year. There may be a relationship between actual experienced inflation rates and individuals' expected future inflation rates, but from these results it does not appear to be a simple one.

A third interesting result, captured in columns (4)-(6), is that knowledge of or interest in economic issues does appear to affect inflation expectations. Respondents were asked about their knowledge of the Bank of Japan's 2\% inflation target introduced in January 2013, their level of interest in economic issues generally, Abenomics ${ }^{11}$ and their knowledge of the Statistics Bureau's CPI. Responses to all these questions are entered as dummy variables in the regression model of Table 5. The base category for "Knows About BOJ's 2\% Inflation Target" is "knows well about the BOJ target," for "Interested In Economic Issues" it is "is interested and follows the news," for "Knows About Abenomics" it is "knows well about Abenomics," and for "Interested In CPI" it is "interested in the CPI and follows it."

Looking first at column (4), one can see that those with greater knowledge of the BOJ's $2 \%$ inflation target reported higher expected inflation rates. This result suggests that an explicit inflation target from the central bank may be effective in affecting the inflation expectations of consumers. In column (5), when we add variables measuring the degree of interest that respondents have in economic issues in general, we find that those with greater interest have higher expected inflation rates. On the other hand, the effect of the BOJ's inflation target is weakened.

In column (6), the estimated coefficients on the "Knows About Abenomics" variables suggest that those with more knowledge of Abenomics have higher inflation expectations. In fact, the estimated difference in expected inflation between those who know about Abenomics well and those who know nothing about it is more than 3 percentage points, a remarkable difference. Similarly, those who take a greater interest in the Statistics Bureau's published CPI figures also report higher expected inflation rates.

However, it appears as though once knowledge of Abenomics and the CPI are accounted for, neither particular knowledge of the BOJ's $2 \%$ inflation target nor general

\footnotetext{
${ }^{11}$ The economic policies of the Abe administration, made public in December 2012
} 
interest in economics has a statistically significant effect on expected inflation. But since many of these variables are highly correlated it is difficult to dismiss the possibility that the central bank's inflation target does affect consumers' inflation expectations. Furthermore, if the $2 \%$ target were affecting inflation expectations one would expect the effect to depend on the individual's level of inflation expectations. In particular, one might expect the effect to be positive for those with inflation expectations below the BOJ's target and negative for those with expectations above the BOJ's target. We investigate this matter further in the appendix and our results suggest that inflation targeting is indeed effective in moving inflation expectations towards the target range. We also show that the effect of inflation targeting is different between younger and older individuals. In particular, inflation targeting is more effective in reducing high inflation expectations among older individuals and more effective in raising low inflation expectations towards the target range among younger individuals.

Although the estimated coefficient on the household inflation rate suggests that it has no effect on inflation expectations, it is possible that the coefficient is biased because of the data used to measure the household inflation rate. The scanner data fail to collect numerous items, including goods without barcodes, goods with barcodes not observed in both years and services. As a robustness check on our results we replace the household inflation rate measured using the scanner data with the inflation rate by age group of household head, calculated from the CPI. ${ }^{12}$ The CPI by age group of household head includes numerous items not captured by our scanner data, such as services and goods without barcodes.

The results of using the inflation rate by age group of household head in place of the household inflation rate using the scanner data are presented in column (7) of Table 5. In contrast to the results using the scanner data, the estimated coefficient on the lagged inflation variable is now statistically significant and economically large. However, the estimated coefficients on all other variables are very similar to the those in columns (1) - (6). In particular, the estimated coefficient on the age variable is very close to that

\footnotetext{
${ }^{12}$ The age groups are: less than 29, 30-39, 40-49, 50-59, 60-69 and 70 and older.
} 
estimated using the scanner data.

Although their data do not allow them to do so, Kaplan and Schulhofer-Wohl (2017) speculate that differences in realized inflation rates might explain differences in inflation expectations. Since we are able to calculate the inflation rate in both 2013 and 2014, we can test this hypothesis by replacing the household's realized inflation rate over the past year with the realized inflation rate during the following year. The results of this exercise are reported in columns (8) - (10) of Table 5. The results are very similar to those in columns (4) - (6). They indicate that there is almost no correlation between future realized inflation rates and inflation expectations, rejecting the hypothesis speculated in Kaplan and Schulhofer-Wohl (2017) that the variation in household inflation expectations is driven by the variation in foreseeable future inflation rates.

\section{Disentangling Age Effects from Cohort Effects}

Thus far we have observed a robust correlation between age and inflation expectations, even controlling for actual experienced inflation. What could account for this correlation? One possibility is that age differences in realized inflation rates actually do explain all of the differences in inflation expectations, but we have mismeasured true householdlevel inflation rates because we do not include in our measure of inflation a number of items that should be included, such as services, goods without barcodes and goods bought in one year but not in the other. If the measurement error is classical then the measured coefficient on the household inflation rate will be biased downwards.

Another possibility is that those of the same age have shared historical experiences and what appears to be a correlation between age and inflation expectations might actually be a correlation between shared historical experiences and inflation expectations. In particular, it may be the case that experiences of high inflation affect the inflation expectations of individuals long into the future. This perspective was emphasized by Ryder (1965), who argued that "each cohort has a distinctive composition and character reflecting the circumstances of its unique origination and history." For the question at 
hand the shared history of interest is the macroeconomic (particularly inflation) history experienced by each cohort and we can imagine that those who have experienced episodes of high inflation may carry with them an upward bias to their inflation expectations throughout their lives. In contrast, young Japanese, who have only ever experienced low rates of inflation, may underestimate the potential of higher inflation rates in the future.

\subsection{Individuals' Experienced Lifetime Inflation Rates}

This perspective reinterprets the age effect observed in our data as a cohort effect. However, estimating the effects of age, cohort and time in a simple linear additive model is not possible because, by definition, Age $=$ Cohort + Time, resulting in perfect collinearity. Researchers have attempted various approaches to overcome this difficulty. Most studies, such as Deaton and Paxson (1994) and McKenzie (2006) ultimately rely on one normalization or another to separate the three effects of age, cohort and time. In response to these approaches, Heckman and Robb (1985) argue that age, cohort and time in the above equation are simply proxies for variables that we are interested in but may not be able to measure directly. Their recommendation is that the researcher define clearly how age, cohort or time is related to the variable of interest (in this case, expected inflation) and try to measure the underlying relationship more directly. In our present case, we propose that the relationship between age and inflation expectations is a convenient substitute for the relationship between the actual inflation rate experienced by an individual and his inflation expectations. This occurs because different age groups tend to consume different baskets and the "age effect" is in essence a "basket effect."

On the other hand, the "cohort effect" reflects the impact of the experience of economic events shared by people at a particular point in history. It may be the case that individuals' expectations of future inflation outcomes are influenced by their experiences of inflation in the past. Those who have experienced high rates of inflation may assign higher probabilities to future high inflation outcomes and may view high inflation as a 
greater threat than those who have not experienced high inflation. Figure 10 summarizes the Japanese inflation experience since World War II. One can observe periods of very high inflation immediately after the war and again in the wake of the oil shocks of the 1970s. One can also observe significantly higher average inflation rates in the decades after World War II compared to the last 30 years.

In short, Figure 10 shows that, generally speaking, older individuals have experienced higher inflation rates during their lifetimes than younger individuals in Japan. Thus, the observed correlation between age and inflation expectations from Table 5 may be masking a correlation between experienced inflation and inflation expectations. What we would like to investigate is the individual's experienced rate of inflation over his lifetime. However, we do not have these data. We can, however, investigate the relationship between the inflation rate of the macroeconomy over an individual's lifetime and his expected future inflation rate. But in order to do this, we need a parsimonious way of summarizing the rate of inflation experienced by an individual over his lifetime.

Honkapohja and Mitra (2003) suggests that this is best accomplished by using a weighted average of the inflation rate over the individual's lifetime. In order to capture the idea that the most recent data are most relevant for the individual while past data are less important, we follow Malmendier and Nagel (2011) and calculate the weighted average of past inflation rates for individual $i$ aged $a_{i t}$ in year $t$ as

$$
\pi_{i t}^{w}(\lambda)=\sum_{s=1}^{a_{i t}-1} \omega_{i t}(s, \lambda) \pi_{t-s}
$$

where $\omega_{i t}(s, \lambda)=\frac{\left(a_{i t}-s\right)^{\lambda}}{\sum_{s=1}^{a_{i t}-1}\left(a_{i t}-s\right)^{\lambda}}$ and $\pi_{t-s}$ is the inflation rate of the macroeconomy in year $t-s$. The weighting parameter $\lambda$ controls the shape of the weighting function.

One can interpret this specification as a special case of the model presented in Marcet and Sargent (1989). In our version, individuals use only inflation data generated during their own lifetimes and place more importance on recent inflation rates than on data from further in the past. In Table 6 we rerun the regressions of Table 5, but replace age with 
the weighted average inflation rate of the macroeconomy over the individual's lifetime, as described in Equation (7). We use the parameter values estimated in Malmendier and Nagel (2016), setting the (implied) value of $\lambda$ equal to 1.834 in columns (1)-(4) and equal to 1.433 in columns (5)-(8). We use the inflation rate excluding imputed rent because it has a longer series and both the series including imputed rent and excluding imputed rent are very similar.

One can observe a strong correlation between the weighted average inflation rate over an individual's lifetime and his future expected inflation rate, even after controlling for his actual experienced rate of inflation over the previous year. The estimated coefficients on the weighted lifetime inflation rate suggest that a one percentage point increase in the weighted lifetime inflation rate increases future inflation expectations by 0.837 to 1.022 percentage points (columns (4) and (8)). These results suggests that, indeed, the observed correlation between age and inflation expectations of Table 5 may reflect the impact of the individual's historical inflation experience on his future inflation expectations.

\subsection{Additional Evidence From a Panel Data Analysis}

One shortcoming of the analysis thus far is that we have relied on cross-sectional data. To really tackle the issue of dependency among age, cohort and time we need to include a time series dimension to the above analysis. To this end we use the Consumer Confidence Survey, a household-level survey conducted monthly since 2004 by the Cabinet Office of the Japanese government. The survey collects data on 8400 households using a three-

level stratified random sampling method based on city/town/village, local unit and household representing the entire Japanese population excluding foreigners, students and institutionalized households (based on the Population Census). Households are surveyed for 15 months continuously before being replaced in the survey. Similarly to the survey used above, respondents are asked to provide their expectations for the change in prices of the goods that they usually buy over the following year by selecting 
the appropriate range. The responses to the March 2014 survey are presented in Table $7 . .^{13}$

Comparing the two samples, one can observe that the distributions are similar for expected inflation rates of less than $0 \%$. However, the right halves of the distributions display significant differences. For example, whereas $9 \%$ of the Intage sample expected the inflation rate to be above $10 \%$, only $5.5 \%$ of respondents in the CCS sample did. Similar proportions of respondents believed that the inflation rate would be between $5 \%$ and $10 \%$ ( $27.8 \%$ of the Intage sample compared to $25.4 \%$ of the CCS sample), but the proportion of respondents who believed that inflation would be between $2 \%$ and $5 \%$ was $29.8 \%$ for the Intage sample compared to $44.7 \%$ for the CCS sample. While $8.7 \%$ of the Intage sample expected the inflation rate to be between $0 \%$ and $2 \%, 12.8 \%$ of respondents in the CCS sample did. Finally, $22 \%$ of the Intage sample expected the inflation rate to be $0 \%$ while only $4.5 \%$ of respondents in the CCS sample did. To summarize the most significant differences between the two distributions, the Intage distribution displays relatively more weight in the $0 \%$ basket, whereas the CCS sample displays relatively more weight in the $2 \%-5 \%$ basket.

One reason for this difference might be that the underlying populations are different. Table 8 compares demographic data on the two samples. The first point to notice is that the respondents in the Consumer Confidence Survey (CCS) are older. Since the CCS is aimed at the household head, the sample displays a far greater representation of men than does the Intage data. Since the household income data are not collected in the same way it is difficult to make exact comparisons, but when we adjust the income data for the CCS to be similar in definition to the Intage data, it appears as though the respondents in the CCS have lower income levels in general.

Thus, it appears as though the two samples represent slightly different underlying populations and this must be considered when interpreting the coefficients estimated using the CCS. While the CCS offers a advantage over the Intage data because it allows us to exploit the time series dimension of the data, it also comes with a disadvantage

\footnotetext{
${ }^{13}$ We use the March 2014 survey because it matches the timing of the survey used earlier in the paper.
} 
as we can no longer observe the actual inflation rates experienced by individuals as we could in the Intage dataset. One may worry that by not controlling for the actual inflation rate experienced by households we are introducing a bias into our estimates. However, the results from Table 5 and Table 6 suggest that once our variables of interest are included, the actual inflation experienced is uncorrelated with the expected rate of inflation and thus there ought not to be any significant bias. Nevertheless, the fact that we cannot control for the individual's inflation rate must be kept in mind in interpreting the results that follow. ${ }^{14}$

Figure 11 introduces graphically the elements of the data upon which we will focus. The first panel of Figure 11 graphs the mean response to the question regarding inflation expectations summarized in Table 7 across age for selected cohorts. We replace the bin number with its midpoint and, as such, the graph does not describe mean inflation expectations, but rather the mean of the midpoints of the bins for inflation expectations, as described in Table 7. For the endpoints, we used the smallest value in the case of the bin with the highest inflation expectations and we used the largest value in the case of the bin with the lowest inflation expectations. Thus, individuals who selected "1," corresponding to the lowest expected range of inflation (less than $-5 \%$ ), were assigned a value of $-5 \%$ and those who selected " 7, " corresponding to the highest expected range of inflation (greater than 5\%), were assigned a value of $5 \% .{ }^{15}$ Those who selected "6," corresponding to an expected inflation rate of between $2 \%$ and $5 \%$ were assigned a value of $3.5 \%$. One can observe a consistent pattern regardless of which cohort one looks at. As the cohort gets older its inflation expectations tend to rise.

The middle panel of Figure 11 graphs the mean expected inflation rate over time for selected age groups. Here one can observe a rising trend between 2004 and 2008, followed by a sharp decline during the Global Financial Crisis of 2009-2010 and a return to a rising trend from 2011 to 2015 for all age groups.

\footnotetext{
${ }^{14}$ We repeated the regression analysis of Table 6 using the CCS data and found similar results to those in Table 6. Results not reported in this paper.

${ }^{15}$ In 2009 the ranges used to inquire about inflation expectations were changed. In order to use as much data as possible, we convert the post-2008 data to be consistent with the pre-2009 data. Thus, the ranges described here are different from those in Table 7.
} 
Finally, the third panel of Figure 11 graphs the mean expected inflation rate across cohorts for selected age groups. Here, too, we observe a rising trend in inflation expectations as we move from older cohorts (those born in earlier years) to younger cohorts (those born in later years). While suggestive, one cannot make any hard conclusions from these graphs. For example, while the third panel of Figure 11 appears to show that inflation expectations rise as we move from older to younger cohorts, the middle panel of Figure 11 suggests that this may have been driven by a general rise in inflation expectations across all age groups and cohorts over time.

The difficulty of solving the perfect collinearity problem among age, cohort and time has led researchers to consider multiple approaches to the problem. One such approach is that of McKenzie (2006), who points out that although the age, cohort and time effects themselves may not be identifiable, the slopes of these effects are identifiable through a strategy of taking the basic linear framework

$$
y_{i, c_{j-k+1}, a_{j}, t_{k}}=\alpha_{c_{j-k+1}}+\beta_{a_{j}}+\gamma_{t_{k}}+\epsilon_{i, c_{j-k+1}, a_{j}, t_{k}}
$$

where $y_{i, c_{j-k+1}, a_{j}, t_{k}}$ is the expected inflation rate of individual $i$ in age group $a_{j}$ and cohort $c_{j-k+1}$ in time period $t_{k}$ and averaging the equation over individuals within a cohort. With the individual-specific effect removed, one then takes second differences to extract the change in the slopes of the age, cohort and time effects. Applying this approach to the Consumer Confidence Survey results in the slopes depicted in Figure 12.

Comparing the two effects, one can observe far greater variation in the age effects than in the cohort effects. However, the age effects also have wider confidence intervals, with many of them containing zero. This implies that we cannot reject the hypothesis that the second differences are equal to zero. The only age groups whose estimated second differences are statistically significantly different from zero are the 41-year old group (containing ages 39, 40 ad 41) and the 65-year old group (containing ages 63, 64 and 65). Both of these groups have a positive estimated second difference. The latter 
group includes many new retirees who are entitled to begin receiving public pension benefits. This result suggests that a change in inflation expectations may accompany retirement and the commencement of receiving public pension benefits. On the other hand, the cohort effect profile appears to be cancave for the 1924 and earlier cohorts as well as the 1990 cohort. ${ }^{16}$ The 1924 and earlier cohorts are those that were young before and during the Second World War. The 1990 cohort grew up after the start of Japan's deflation, in 1995. Our results suggest that there is a significant change in the inflation expectations of those who grew up in the era of deflation compared to other cohorts. For the remaining cohorts, the profile appears to be approximately linear. Our conclusion is that the age-inflation expectations profile is close to linear and the cohort-inflation expectations profile is also approximately linear, with the possibility of concavity around the endpoints.

\subsection{Estimating Cohort Effects Using the Age Profile of Consumption Basket}

In this subsection, we will use the consumption baskets of different age groups as a proxy variable for the age effect, as we did in subsection 3.3. Specifically, we ran a regression using the weight effect from equation (3), estimated with actual scanner data, as a proxy variable for the age effect. We will employ this approach again to avoid the problem of perfect collinearity among age, cohort and time and estimate our central variable of interest - the cohort effect. We present the estimated coefficients and $95 \%$ confidence intervals graphically in the left-hand side panel of Figure 13. Our estimates suggest that the effects are approximately constant over the 1936-1962 cohorts. The cohort effect then declines steadily until the mid-1980s, after which the pace of decline appears to accelerate. The pattern of accelerating decline of the cohort effects from the mid1980s onwards is consistent with the results of the right-hand side panel of Figure 12, which shows a sudden and sharp drop in the second derivative of the cohort profile.

\footnotetext{
${ }^{16} \mathrm{~A}$ Wald test rejects the hypothesis that the second derivatives of all cohorts are zero. Results not presented in this paper.
} 
At this point we need to bear in mind that the scanner data capture only specific items purchased. Thus the weight effect is estimated from a basket that may not accurately represent the household's consumption pattern. As a robustness test, we also use the CPI estimated by age of household head as a proxy variable for the age effect and estimate the same regression as above. Since the CPI estimated by age of household head is calculated by weighting each item in the CPI by the weight in the consumption basket of the relevant age-group, it ensures that heterogeneity among age groups is due only to differences in the weights applied to each item. In other words, it isolates the weight effect. The results, presented in the middle panel of Figure 13, are very similar to those generated when using the weight effect rather than the CPI estimated by age of household head as a proxy variable for the age effect.

Looking at the results that compare the consumption baskets of various age groups using the scanner data (i.e. the weight effect in the left-hand side panel of Figure 5), one does not observe significant differences in terms of the consumption basket between the 60-64 year-old group and the 65-69 year-old group, both of which consist mainly of retirees who receive public pension benefits. This is in contrast with the result that the weight effect of the working-age generation tends to rise with age. A similar tendency can be observed for the CPI estimated by age of household head. To focus more deeply on this result, we perform the following exercise. In contrast to the estimations that we have performed thus far in this subsection, we do not use a proxy variable for the age effect. Instead, we construct dummy variables for each age group, which take a value of 1 if a given observation belongs to that age group and a value of zero if it does not. We then add these dummy variables as explanatory variables to the regression analysis. However, simply adding these variables to the regression will result in perfect collinearity among the regressors. To avoid this problem, we impose the constraint that the coefficients on the dummy variables for age groups above the 60-year old group are all equal. ${ }^{17}$ The results of this estimation are presented in the right-hand side panel of

\footnotetext{
${ }^{17}$ Lagakos et al. (2018) imposes a similar restriction on the age profile of nominal wage in order to disentangle age, cohort, and time effects.
} 
Figure 13. As with the other two estimation exercises, one can observe that the cohortinflation expectations profile is downward sloping, with the inflation expectations of the cohorts after 1970 particularly low.

\subsection{Estimating Cohort Effects Using the Intrinsic Estimator}

We mentioned above that the central difficulty to estimating age, cohort and time effects is that the various approaches employed require the researcher to make an arbitrary normalization in order to break the perfect collinearity among the variables. Yang et al. (2004) proposes a new approach called the "Intrinsic Estimator." This estimator is essentially a principal components approach which shows that any normalization used to identify age, cohort and time effects separately can be understood as a common component and an arbitrary linear trend. This common component is referred to as the intrinsic estimator. We divide our sample into 3-year age groups (18-20, 21-23, etc) and apply the intrinsic estimator to the Consumer Confidence Survey data. ${ }^{18}$ The estimates are presented in Figure $14 .^{19}$

The first panel of Figure 14 suggests that age has an impact on inflation expectations that is independent of the cohort effect. Inflation expectations decrease with age until one's late 30s, then increase suddenly before remaining approximately constant until one's late-80s. Although there does appear to be some variation across age, the range of estimated effects is rather small, differing by only $0.4 \%$ between the largest and smallest values. Combining this with our earlier result that an individual's short-term inflation experience has no effect on their inflation expectations suggests that age affects inflation expectations through some channel other than the consumption basket.

In the second panel of Figure 14, one can observe a gradually increasing cohort effect

\footnotetext{
${ }^{18}$ Age-groups are labelled according to the oldest members of the group so that, for example, the 23 year-old age group contains individuals aged 21, 22, and 23. Cohort-groups are labelled according to the relationship cohort $=$ year-age, so that the cohort label refers to the midpoint of the years of birth of the group. For example, the 1915 cohort includes individuals born in years 1913-1917 and the 1990 cohort includes individuals born in years 1988-1992.

${ }^{19}$ Application of the estimator requires aggregating the individual-level data into age-group-level data. To this end, we assign to each individual an inflation expectation equal to the midpoint of the range selected in Table 7 and then use the mean of this midpoint as the inflation expectation of each age-group.
} 
from the 1915 cohort until the 1951 cohort. There is a sudden drop for the 1954-1966 cohorts, followed by a return to a larger cohort effect for the 1969 cohort. Thereafter, the cohort effect declines substantially until the 1993 cohort.

From 1981 onwards, all cohorts exhibit a negative cohort effect on inflation expectations. These individuals were no older than 16 when Japan's inflation rate first approached zero during the mid-1990s. In other words, most of them have known nothing but deflation and extremely low levels of inflation. The estimated coefficients suggest that the cohort effect alone increases inflation expectations by approximately 0.8 percentage points for the cohort with the largest cohort effect (1969) compared to the cohort with the smallest cohort effect (1993).

The main takeaway from Figure 14 is that those cohorts who have only ever experienced deflation or very low rates of inflation have the smallest cohort effects. Those cohorts who experienced higher rates of inflation, including the two oil shocks of the 1970s, appear to exhibit systematically larger cohort effects.

\section{Inflation Expectations In An Era Of Deflation}

Japan has experienced deflation for the last two decades. The results of this study suggest that the deflationary experience has pushed down consumers' inflation expectations and that this effect has been most dramatic for those who have grown up in the era of deflation. Figures 13 and 14 suggest a break in the cohort effect on inflation expectations from the late 1970s and the most striking difference in the inflation experience of the cohorts before this break and the cohorts after this break is that the younger cohorts have lived almost entirely in a period of deflation.

One implication of these results is that the longer the era of deflation continues, the lower will the population's inflation expectations become. Subdued inflation expectations will become more and more entrenched as aging ensures that those who have experienced periods of high inflation become a smaller part of the population. Low inflation expectations may become entrenched as the public memory of high inflation fades. 
To the extent that it is a goal of monetary policy to raise inflation expectations, taking more aggressive action earlier on can reduce the risk of allowing low inflation (and even deflation) expectations to become entrenched through experience and requiring more aggressive action in the future.

Fortunately, the results of the following section suggest that monetary policy is not impotent in the face of this trend.

\section{Inflation Targeting and Inflation Expectations}

In this section we investigate more closely the relationship between individuals' knowledge of the Bank of Japan's 2\% inflation target and their inflation expectations for the following year. In Table 5 we showed that individuals with more knowledge of the BOJ's inflation target tended to have higher inflation expectations, but that the effect appeared to disappear when we controlled for other information variables, such as knowledge of Abenomics and knowledge of the CPI.

However, if the $2 \%$ target were affecting inflation expectations one would expect the effect to be positive for those with inflation expectations below the BOJ's target and negative for those with expectations above the BOJ's target. In order to investigate this possibility, we estimate a multinomial logit version of the basic model in Equation (5) and report the results in Table 9.

The three columns of Table 9 correspond to columns (4)-(6) of Table 5 so that, while not reported in Table 9, all the control variables of columns (4)-(6) in Table 5 are included in Table 9. The base category is the expectation that the inflation rate will be within the BOJ's inflation target of 0\%-2\%. The results show that those most aware of the BOJ's inflation target are relatively less likely to expect an inflation rate outside of the BOJ's target range of $0 \%-2 \%$. Although the results are generally not statistically significant for cases where the expected inflation rate is less than $-2 \%$, this may simply be a matter of small sample size since there are very few individuals who expect inflation rates in this range. The point estimates, however, are largely consistent with the results 
in the rest of the table. The broad conclusion from this exercise is that individuals who are more knowledgeable of the Bank of Japan's inflation target are relatively more likely to predict that their own inflation rates over the following year will fall within the BOJ's target range rather than any other range.

In Figure 15 we estimate the model used to generate the results of Table 9 separately for those aged 30 or less and those older than 30 and plot the predicted probabilities of inflation expectations falling within a given range. ${ }^{20}$ The slopes of the figure show that for both those 30 years old and under and those older than 30 years of age, knowing about the BOJ's $2 \%$ inflation target increases the predicted probability of expecting inflation in the $0 \%-2 \%$ and $2 \%-5 \%$ ranges, close to the BOJ's $2 \%$ target.

Comparing the predicted probabilities of expecting deflation between those 30 years old and under and those older than 30 years of age, one can see that the slope of the curve is steeper for the younger group, suggesting that the inflation target is particularly effective in suppressing expectations of deflation among the young. On the other hand, the slopes of the curves are steeper for the older age group within the 5\%-10\% inflation expectation category. One can interpret these results as implying that the BOJ's inflation target is more effective at decreasing moderately high inflation expectations among older individuals than younger individuals, but that it is more effective at raising expectations among young people expecting deflation than it is at raising expectations among older people expecting deflation. This suggests an asymmetry in the effects of inflation targeting across age groups. However, whether this is an age effect or a cohort effect cannot be determined here, but is an interesting question for the future efficacy of monetary policy.

\footnotetext{
${ }^{20}$ Because of the small sample size of those expecting deflation, we combine those who expect deflation and those who expect $0 \%$ inflation into one group. The predicted probabilities are generated by estimating the model at the mean values of the control variables.
} 


\section{Conclusion}

This study uses a new dataset on inflation expectations, combined with individual-level purchase data and demographic data to construct age-group-specific price levels and age-group-specific inflation rates. Our results show that the price level for the common basket of goods tends to be constant until age 40-44 and then begins to rise thereafter, possibly peaking at age 65 . The household inflation rate also varies across age groups and generally rises with age, reaching a peak at age 55-59.

In investigating the source of variation in inflation rates across age, we found that the most important source of variation comes from differences in weights - i.e. differences in the amounts consumed of different goods in the same common basket. This suggests that older individuals face higher inflation rates, not so much because they consume items with high inflation rates that younger workers do not consume (although this is one source of the variation), but because they consume more of the high inflation rate items that all other age groups also consume (although in smaller quantities).

However, even though older individuals experience higher rates of inflation, we found that the difference in inflation rates across age groups is not sufficient to explain the positive correlation between inflation expectations and age. Even controlling for the household's experienced rate of inflation, we continue to find a statistically significant positive correlation between age and expected inflation rates.

Using the Japanese Consumer Confidence Survey, we investigated the possibility that the positive correlation between age and inflation expectations is due to shared historical inflation experiences, akin to a cohort effect, rather than a true age effect. We found that individuals' expectations of future inflation rates are strongly correlated with the inflation rate of the macroeconomy over their lifetimes, suggesting that, at least to some degree, individuals' expectations of future inflation rates are influenced by the inflation rates that they have actually experienced. This conclusion was supported by the finding that variation in the estimated cohort effects could be matched to historical episodes of inflation and deflation. 
Finally, we also investigated the relationship between knowledge of the central bank's inflation targeting policy and inflation expectations and found that individuals who are more informed about the central bank's policy are relatively more likely to have inflation expectations that fall within the central bank's target range. While not conclusive, this suggests that the Bank of Japan's communication strategy my have been effective in altering inflation expectations. The finding that the central bank's inflation targeting policy appears more effective at altering low inflation expectations among younger individuals than older individuals raises the possibility that this is a tool of monetary policy that will grow more important over time.

These findings carry implications for both monetary policy and the structure of the social safety net. In the case of monetary policy, while it appears that communication of an inflation target may affect individuals' inflation expectations, there is little that a central bank can do to change the historically experienced inflation rates of individuals. On the other hand, to the extent that the central bank can affect inflation outcomes, it does have the power to change the historically experienced inflation rates of future generations. Furthermore, as Japan's population continues to age, more and more of the population will have experienced only low rates of inflation (or even deflation), making it more difficult to raise expectations to a level that the central bank believes is appropriate.

On the matter of the social safety net, our results raise the question of whether social security and retirement benefits should be indexed to the general rate of inflation or adjusted higher for older individuals, who face higher inflation rates than the general population. Choosing the latter would place an even greater burden on the country's public finances and the questions of fairness and prudence in the management of public resources would need to be carefully considered.

Our analysis also begs new questions about the relationship between inflation expectations and realized inflation rates. For example, how well are households able to predict their own future inflation rates? Another important question is how accurately 
households perceive their own experienced rates of inflation. Although not tackled in this study, these questions are important avenues of future research. 


\section{References}

Naohito Abe and Kyosuke Shiotani. Who Faces Higher Prices? An Empirical Analysis Based on Japanese Homescan Data. Asian Economic Policy Review, 9(1):94-115, 2014 .

Mark Aguiar and Erik Hurst. Life-Cycle Prices and Production. The American Economic Review, 97(5):1533-1559, 2007.

Alan G Ahearne, Joseph Gagnon, Jane Haltmaier, Steven B Kamin, Christopher J Erceg, Jon Faust, Luca Guerrieri, Jennifer E Roush, John H Rogers, Nathan Sheets,

et al. Preventing Deflation: Lessons from Japan's Experience in the 1990s. FRB International Finance Discussion Paper, (729), 2002.

Takeshi Amemiya. Regression Analysis when the Dependent Variable Is Truncated Normal. Econometrica: Journal of the Econometric Society, pages 997-1016, 1973.

Jess Benhabib, Stephanie Schmitt-Grohé, and Martin Uribe. The Perils of Taylor Rules. Journal of Economic Theory, 96(1):40-69, 2001.

Jess Benhabib, Stephanie Schmitt-Grohé, and Martin Uribe. Avoiding Liquidity Traps. Journal of Political Economy, 110(3):535-563, 2002.

Alan S Blinder. Central-Bank Credibility: Why Do We Care? How Do We Build It? American Economic Review, pages 1421-1431, 2000.

Christopher D Carroll. The Epidemiology of Macroeconomic Expectations. In Larry Blume and Steven Durlauf, editors, The Economy as an Evolving Complex System, III. Oxford University Press, 2006.

Timothy Cogley and Thomas J Sargent. The Market Price of Risk and the Equity Premium: A Legacy of the Great Depression? Journal of Monetary Economics, 55 (3):454-476, 2008. 
Angus S Deaton and Christina Paxson. Saving, Growth, and Aging in Taiwan. In Studies in the Economics of Aging, pages 331-362. University of Chicago Press, 1994.

Gauti B Eggertsson and Michael Woodford. The Zero Bound on Interest Rates and Optimal Monetary Policy. Brookings Papers on Economic Activity, 2003(1):139-233, 2003.

Milton Friedman. A Theory of the Consumption Function. Oxford \& IBH Publishing Company, 1957.

Milton Friedman and Anna Jacobson Schwartz. A Monetary History of the United States, 1867-1960. Princeton University Press, 1963.

Paola Giuliano and Antonio Spilimbergo. Growing up in a Recession. The Review of Economic Studies, 81(2):787-817, 2014.

Robin Greenwood and Stefan Nagel. Inexperienced Investors and Bubbles. Journal of Financial Economics, 93(2):239-258, 2009.

Ernan Haruvy, Yaron Lahav, and Charles N Noussair. Traders' Expectations in Asset Markets: Experimental Evidence. The American Economic Review, 97(5):1901-1920, 2007.

James Heckman and Richard Robb. Using Longitudinal Data to Estimate Age, Period and Cohort Effects in Earnings Equations. In Cohort Analysis in Social Research, pages 137-150. Springer, 1985.

Seppo Honkapohja and Kaushik Mitra. Learning with Bounded Memory in Stochastic Models. Journal of Economic Dynamics and Control, 27(8):1437-1457, 2003.

Takeo Hoshi and Anil Kashyap. What Stopped Japan's Economic Growth? Prescriptions for the Revival (Nani ga Nihon no Keizai Seichō o Tometa no ka-Saisei e no Shohōsen). Nihon Keizai Shimbun, 2013. 
Takatoshi Ito and Frederic S Mishkin. Two Decades of Japanese Monetary Policy and the Deflation Problem. In Monetary Policy with Very Low Inflation in the Pacific Rim, NBER-EASE, Volume 15, pages 131-202. University of Chicago Press, 2006.

Benjamin Kramer Johannsen. Inflation Experience and Inflation Expectations: Dispersion and Disagreement Within Demographic Groups. 2014.

Taehun Jung, Yuki Teranishi, and Tsutomu Watanabe. Optimal Monetary Policy at the Zero-Interest-Rate Bound. Journal of Money, Credit, and Banking, 37(5):813-835, 2005 .

Greg Kaplan and Sam Schulhofer-Wohl. Inflation at the household level. Journal of Monetary Economics, 91:19-38, 2017.

John Maynard Keynes. The General Theory of Interest, Employment and Money. London: Macmillan, 1936.

Paul R Krugman. It's Baaack: Japan's Slump and the Return of the Liquidity Trap. Brookings Papers on Economic Activity, 1998(2):137-205, 1998.

Haruhiko Kuroda. How to Overcome Deflation. Speech at a Conference Held by the London School of Economics and Political Science in London, March 2014.

David Lagakos, Benjamin Moll, Tommaso Porzio, Nancy Qian, and Todd Schoellman. Life Cycle Wage Growth Across Countries. Journal of Political Economy, 126(2): 797-849, 2018.

Ulrike Malmendier and Stefan Nagel. Depression Babies: Do Macroeconomic Experiences Affect Risk-Taking? The Quarterly Journal of Economics, 126(1):373-416, 2011.

Ulrike Malmendier and Stefan Nagel. Learning from Inflation Experiences. The Quarterly Journal of Economics, 131(1):53-87, 2016. 
N Gregory Mankiw, Ricardo Reis, and Justin Wolfers. Disagreement about Inflation Expectations. In NBER Macroeconomics Annual 2003, Volume 18, pages 209-270. The MIT Press, 2004.

Albert Marcet and Thomas J Sargent. Convergence of Least Squares Learning Mechanisms in Self-Referential Linear Stochastic Models. Journal of Economic theory, 48 (2):337-368, 1989 .

David J McKenzie. Disentangling Age, Cohort and Time Effects in the Additive Model. Oxford Bulletin of Economics and Statistics, 68(4):473-495, 2006.

Norman B Ryder. The Cohort as a Concept in the Study of Social Change. American Sociological Review, pages 843-861, 1965.

Thomas J Sargent. The Ends of Four Big Inflations. In Inflation: Causes and effects, pages 41-98. University of Chicago Press, 1982.

Vernon L Smith, Gerry L Suchanek, and Arlington W Williams. Bubbles, Crashes, and Endogenous Expectations in Experimental Spot Asset Markets. Econometrica, pages $1119-1151,1988$.

Lars EO Svensson. The Zero Bound in an Open Economy: A Foolproof Way of Escaping from a Liquidity Trap. Technical report, National Bureau of Economic Research, 2000.

Leo Törnqvist. The Bank of Finland's Consumption Price Index. Bank of Finland Monthly Bulletin, 10:1-8, 1936.

Yuko Ueno and Ryoichi Namba. Disagreement and Biases in Inflation Expectations of Japanese Households (in Japanese). ESRI Discussion Papers No.300. Economic Research Institute. Cabinet Office. Government of Japan., 2013.

Annette Vissing-Jorgensen. Perspectives on Behavioral Finance: Does "Irrationality" Disappear with Wealth? Evidence from Expectations and Actions. In NBER Macroeconomics Annual 2003, Volume 18, pages 139-208. The MIT Press, 2004. 
Michael Woodford. Interest and Prices: Foundations of a Theory of Monetary Policy. Princeton University Press, 2003.

Yang Yang, Wenjiang J Fu, and Kenneth C Land. A Methodological Comparison of Age-Period-Cohort Models: The Intrinsic Estimator and Conventional Generalized Linear Models. Sociological Methodology, 34(1):75-110, 2004. 
Table 1: Summary Statistics

\begin{tabular}{|c|c|c|c|c|}
\hline Variable & Mean & Std. Dev. & Min. & Max. \\
\hline Age & 47.36 & 11.886 & 17 & 69 \\
\hline Male & 0.518 & 0.5 & 0 & 1 \\
\hline Married & 0.687 & 0.464 & 0 & 1 \\
\hline Completed High School & 0.259 & 0.438 & 0 & 1 \\
\hline Completed Technical High School & 0.036 & 0.187 & 0 & 1 \\
\hline Completed Technical College & 0.12 & 0.325 & 0 & 1 \\
\hline Completed Junior College & 0.119 & 0.324 & 0 & 1 \\
\hline Completed College & 0.397 & 0.489 & 0 & 1 \\
\hline Completed Graduate School & 0.043 & 0.202 & 0 & 1 \\
\hline Regular Employee & 0.391 & 0.488 & 0 & 1 \\
\hline Self Employed/Owner & 0.074 & 0.262 & 0 & 1 \\
\hline Contract Employee & 0.072 & 0.259 & 0 & 1 \\
\hline Other Employee & 0.03 & 0.17 & 0 & 1 \\
\hline Part Time/Arubaito & 0.155 & 0.362 & 0 & 1 \\
\hline Stay-At-Home & 0.176 & 0.381 & 0 & 1 \\
\hline Student & 0.012 & 0.11 & 0 & 1 \\
\hline Unemployed & 0.09 & 0.286 & 0 & 1 \\
\hline Household Income $<¥ 4$ Million & 0.301 & 0.459 & 0 & 1 \\
\hline Household Income $¥ 4$ Million- $¥ 5.5$ Million & 0.203 & 0.402 & 0 & 1 \\
\hline Household Income $¥ 5.5$ Million- $¥ 7$ Million & 0.162 & 0.369 & 0 & 1 \\
\hline Household Income $¥ 7$ Million- $¥ 9$ Million & 0.158 & 0.365 & 0 & 1 \\
\hline Household Income > ¥9 Million & 0.174 & 0.379 & 0 & 1 \\
\hline
\end{tabular}

Note: Data from Intage Survey.

Table 2: 1-Year Ahead Inflation Expectations I

\begin{tabular}{clcccc}
\hline \hline Answer No. & \multicolumn{1}{c}{ Answer } & Mean & Std. Dev. & Min. & Max. \\
\hline 1 & Prices will probably rise substantially & 0.152 & 0.360 & 0 & 1 \\
2 & Prices will probably rise slightly & 0.601 & 0.490 & 0 & 1 \\
3 & Prices will probably hardly change & 0.220 & 0.414 & 0 & 1 \\
4 & Prices will probably fall slightly & 0.023 & 0.151 & 0 & 1 \\
5 & Prices will probably fall substantially & 0.004 & 0.060 & 0 & 1 \\
\hline N & \multicolumn{2}{c}{13384}
\end{tabular}

Note: Data from Intage Survey. 
Table 3: 1-Year Ahead Inflation Expectations II

\begin{tabular}{cccccc}
\hline \hline Interval & Inflation Rage & Mean & Std. Dev. & Min. & Max. \\
\hline 1 & $>10 \%$ & 0.09 & 0.287 & 0 & 1 \\
2 & $5 \%$ to $10 \%$ & 0.278 & 0.448 & 0 & 1 \\
3 & $2 \%$ to $5 \%$ & 0.298 & 0.457 & 0 & 1 \\
4 & $0 \%$ to $2 \%$ & 0.087 & 0.282 & 0 & 1 \\
5 & Approximately $0 \%$ & 0.22 & 0.414 & 0 & 1 \\
6 & $-2 \%$ to $0 \%$ & 0.012 & 0.108 & 0 & 1 \\
7 & $-5 \%$ to $-2 \%$ & 0.01 & 0.098 & 0 & 1 \\
8 & $-10 \%$ to $-5 \%$ & 0.003 & 0.054 & 0 & 1 \\
9 & $<-10 \%$ & 0.003 & 0.051 & 0 & 1 \\
\hline $\mathrm{N}$ & \multicolumn{5}{c}{13384} \\
\hline
\end{tabular}

Note: Data from Intage Survey. 


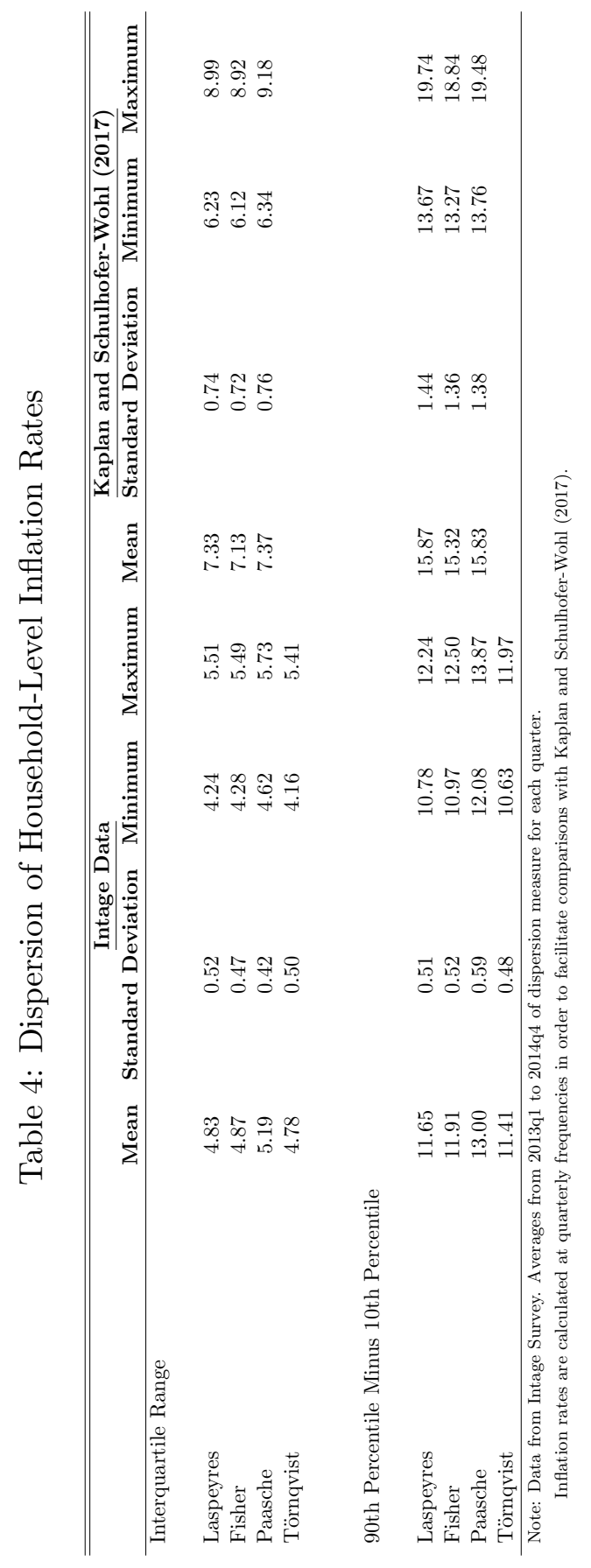


Table 5: Inflation Expectations and Age

\begin{tabular}{|c|c|c|c|c|c|c|c|c|c|c|}
\hline & $(1)$ & $(2)$ & $(3)$ & 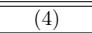 & 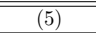 & $\overline{(26)}$ & 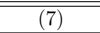 & $(8)$ & $\overline{(29)}$ & $(10)$ \\
\hline Age & $\begin{array}{c}0.050^{* * * *} \\
(0.003)\end{array}$ & $\begin{array}{c}0.050^{* * *} \\
(0.003)\end{array}$ & $\begin{array}{c}0.050^{* * * *} \\
(0.003)\end{array}$ & $\begin{array}{c}0.044^{* * * *} \\
(0.003)\end{array}$ & $\begin{array}{c}0.041^{* * *} \\
(0.003)\end{array}$ & $\begin{array}{c}0.041^{* * * *} \\
(0.004)\end{array}$ & $\begin{array}{c}0.048^{* * * *} \\
(0.004)\end{array}$ & $\begin{array}{c}0.043^{* * *} \\
(0.004)\end{array}$ & $\begin{array}{c}0.040^{* * * *} \\
(0.004)\end{array}$ & $\begin{array}{c}0.040^{* * *} \\
(0.004)\end{array}$ \\
\hline Household Inflation Rate & & $\begin{array}{l}-0.002 \\
(0.011)\end{array}$ & $\begin{array}{c}0.000 \\
(0.011)\end{array}$ & $\begin{array}{l}-0.001 \\
(0.011)\end{array}$ & $\begin{array}{l}-0.001 \\
(0.011)\end{array}$ & $\begin{array}{c}0.000 \\
(0.011)\end{array}$ & & & & \\
\hline Inflation Rate by Age of Household Head & & & & & & & $\begin{array}{l}2.944^{*} \\
(1.269)\end{array}$ & & & \\
\hline 1-Year Ahead Household Inflation Rate & & & & & & & & $\begin{array}{c}-0.004 \\
(0.011)\end{array}$ & $\begin{array}{c}-0.003 \\
(0.011)\end{array}$ & $\begin{array}{c}-0.002 \\
(0.011)\end{array}$ \\
\hline Male & & & $\begin{array}{c}-0.237^{*} \\
(0.099)\end{array}$ & $\begin{array}{c}-0.394^{* * *} \\
(0.101)\end{array}$ & $\begin{array}{c}-0.419^{* * *} \\
(0.101)\end{array}$ & $\begin{array}{c}-0.389^{* * * *} \\
(0.100)\end{array}$ & $\begin{array}{c}-0.392^{* * *} \\
(0.100)\end{array}$ & $\begin{array}{c}-0.415^{* * *} \\
(0.104)\end{array}$ & $\begin{array}{c}-0.440^{* * *} \\
(0.104)\end{array}$ & $\begin{array}{c}-0.408^{* * * *} \\
(0.103)\end{array}$ \\
\hline Married & & & $\begin{array}{c}0.090 \\
(0.088)\end{array}$ & $\begin{array}{c}0.091 \\
(0.087)\end{array}$ & $\begin{array}{c}0.078 \\
(0.087)\end{array}$ & $\begin{array}{c}0.059 \\
(0.087)\end{array}$ & $\begin{array}{c}0.042 \\
(0.087)\end{array}$ & $\begin{array}{c}0.100 \\
(0.090)\end{array}$ & $\begin{array}{c}0.084 \\
(0.090)\end{array}$ & $\begin{array}{c}0.065 \\
(0.089)\end{array}$ \\
\hline Knows About BOJ's 2 percent Inflation Target & & & & & & & & & & \\
\hline Knows About Inflation Target Generally & & & & $\begin{array}{c}-0.269 \\
(0.140)\end{array}$ & $\begin{array}{l}-0.122 \\
(0.146)\end{array}$ & $\begin{array}{c}0.225 \\
(0.162)\end{array}$ & $\begin{array}{c}0.211 \\
(0.161)\end{array}$ & $\begin{array}{l}-0.267 \\
(0.144)\end{array}$ & $\begin{array}{l}-0.115 \\
(0.151)\end{array}$ & $\begin{array}{c}0.220 \\
(0.168)\end{array}$ \\
\hline Has Heard About Target & & & & $\begin{array}{c}-0.520^{* * * *} \\
(0.144)\end{array}$ & $\begin{array}{l}-0.175 \\
(0.160)\end{array}$ & $\begin{array}{c}0.349 \\
(0.179)\end{array}$ & $\begin{array}{c}0.325 \\
(0.178)\end{array}$ & $\begin{array}{c}-0.541^{* * * *} \\
(0.149)\end{array}$ & $\begin{array}{l}-0.180 \\
(0.165)\end{array}$ & $\begin{array}{c}0.328 \\
(0.185)\end{array}$ \\
\hline Has Not Heard About Target & & & & $\begin{array}{c}-1.170^{* * * *} \\
(0.165)\end{array}$ & $\begin{array}{c}-0.670^{* * *} \\
(0.183)\end{array}$ & $\begin{array}{l}-0.016 \\
(0.204)\end{array}$ & $\begin{array}{l}-0.029 \\
(0.203)\end{array}$ & $\begin{array}{c}-1.186^{* * *} \\
(0.169)\end{array}$ & $\begin{array}{c}-0.663^{* * *} \\
(0.189)\end{array}$ & $\begin{array}{l}-0.036 \\
(0.211)\end{array}$ \\
\hline Interested In Economic Issues & & & & & & & & & & \\
\hline Not Deeply Interested, But Follows News & & & & & $\begin{array}{l}-0.148 \\
(0.109)\end{array}$ & $\begin{array}{c}0.143 \\
(0.113)\end{array}$ & $\begin{array}{c}0.141 \\
(0.112)\end{array}$ & & $\begin{array}{l}-0.168 \\
(0.113)\end{array}$ & $\begin{array}{c}0.132 \\
(0.117)\end{array}$ \\
\hline Follows The News When Necessary For Work & & & & & $\begin{array}{c}-0.704^{* * *} \\
(0.153)\end{array}$ & $\begin{array}{c}-0.306 \\
(0.157)\end{array}$ & $\begin{array}{l}-0.284 \\
(0.156)\end{array}$ & & $\begin{array}{c}-0.706^{* * *} \\
(0.159)\end{array}$ & $\begin{array}{l}-0.300 \\
(0.163)\end{array}$ \\
\hline Follows The News When Has Free Time & & & & & $\begin{array}{c}-0.558^{* * *} \\
(0.126)\end{array}$ & $\begin{array}{c}-0.071 \\
(0.134)\end{array}$ & $\begin{array}{l}-0.063 \\
(0.133)\end{array}$ & & $\begin{array}{c}-0.595^{* * *} \\
(0.130)\end{array}$ & $\begin{array}{l}-0.099 \\
(0.139)\end{array}$ \\
\hline No Interest At All & & & & & $\begin{array}{c}-0.964^{* * *} \\
(0.175)\end{array}$ & $\begin{array}{l}-0.328 \\
(0.187)\end{array}$ & $\begin{array}{l}-0.319 \\
(0.186)\end{array}$ & & $\begin{array}{c}-1.007^{* * *} \\
(0.179)\end{array}$ & $\begin{array}{l}-0.386^{*} \\
(0.192)\end{array}$ \\
\hline Knows About Abenomics & & & & & & & & & & \\
\hline Knows Generally About Abenomics & & & & & & $\begin{array}{c}-0.361^{*} \\
(0.175)\end{array}$ & $\begin{array}{c}-0.356^{*} \\
(0.175)\end{array}$ & & & $\begin{array}{l}-0.310 \\
(0.180)\end{array}$ \\
\hline Has Heard About Abenomics & & & & & & $\begin{array}{c}-0.503^{* *} \\
(0.192)\end{array}$ & $\begin{array}{c}-0.504^{* *} \\
(0.192)\end{array}$ & & & $\begin{array}{l}-0.444^{*} \\
(0.198)\end{array}$ \\
\hline Has Not Heard About Abenomics & & & & & & $\begin{array}{c}-3.214^{* * * *} \\
(0.531)\end{array}$ & $\begin{array}{c}-3.186^{* * * *} \\
(0.527)\end{array}$ & & & $\begin{array}{c}-3.083^{* * *} \\
(0.555)\end{array}$ \\
\hline Interested In CPI & & & & & & & & & & \\
\hline Knows What CPI Is And Sometimes Checks & & & & & & $\begin{array}{c}-0.622^{* * *} \\
(0.181)\end{array}$ & $\begin{array}{c}-0.615^{* * *} \\
(0.180)\end{array}$ & & & $\begin{array}{c}-0.648^{* * *} \\
(0.188)\end{array}$ \\
\hline Knows What CPI Is But Not Interested & & & & & & $\begin{array}{c}-1.215^{* * * *} \\
(0.187)\end{array}$ & $\begin{array}{c}-1.209^{* * * *} \\
(0.186)\end{array}$ & & & $\begin{array}{c}-1.260^{* * * *} \\
(0.194)\end{array}$ \\
\hline Does Not Know What CPI Is & & & & & & $\begin{array}{c}-1.189^{* * *} \\
(0.210)\end{array}$ & $\begin{array}{c}-1.170^{* * *} \\
(0.209)\end{array}$ & & & $\begin{array}{c}-1.189^{* * * *} \\
(0.217)\end{array}$ \\
\hline Constant & $\begin{array}{c}1.650^{* * * *} \\
(0.139)\end{array}$ & $\begin{array}{c}1.681^{* * *} \\
(0.141)\end{array}$ & $\begin{array}{c}1.754^{* * * *} \\
(0.380)\end{array}$ & $\begin{array}{c}2.772^{* * * *} \\
(0.410)\end{array}$ & $\begin{array}{c}3.102^{* * *} \\
(0.416)\end{array}$ & $\begin{array}{c}3.680^{* * * *} \\
(0.435)\end{array}$ & $\begin{array}{l}2.223^{* *} \\
(0.749)\end{array}$ & $\begin{array}{c}2.871^{* * * *} \\
(0.413)\end{array}$ & $\begin{array}{c}3.217^{* * * *} \\
(0.420)\end{array}$ & $\begin{array}{c}3.771^{* * * *} \\
(0.440)\end{array}$ \\
\hline Occupation Dummies & No & No & Yes & Yes & Yes & Yes & Yes & Yes & Yes & Yes \\
\hline Education Dummies & No & No & Yes & Yes & Yes & Yes & Yes & Yes & Yes & Yes \\
\hline Income Group Dummies & No & No & Yes & Yes & Yes & Yes & Yes & Yes & Yes & Yes \\
\hline Observations & 13384 & 13282 & 13282 & 13282 & 13282 & 13282 & 13384 & 12549 & 12549 & 12549 \\
\hline$\chi^{2}$ & 314.73 & 315.09 & 411.82 & 484.56 & 535.97 & 651.68 & 662.95 & 427.78 & 480.03 & 588.21 \\
\hline \multicolumn{11}{|l|}{$\begin{array}{l}{ }^{*} p<0.05,{ }^{* *} p<0.01,{ }^{* * *} p<0.001 \\
\text { Note: Dependent variable is the } 1 \text {-year ahead expected }\end{array}$} \\
\hline $\begin{array}{l}\text { The base category for the Knows About BOJ's } 2 \% \text { Inflatic } \\
\text { The base category for the Interested In Economic Issues } \\
\text { The base category for the Knows About Abenomics questi } \\
\text { The base category for the Interested In CPI question is "i } \\
\text { Data from Intage Survey. }\end{array}$ & $\begin{array}{l}\text { Target que } \\
\text { lestion is "is } \\
\text { n is "knows } \\
\text { terested in t }\end{array}$ & $\begin{array}{l}\text { stion is "kn } \\
\text { interested a } \\
\text { well about } A \\
\text { he CPI and }\end{array}$ & $\begin{array}{l}\text { ws well abo } \\
\text { nd follows t } \\
\text { bernomics." } \\
\text { follows it." }\end{array}$ & $\begin{array}{l}\text { the BOJ } t \\
\text { e news." }\end{array}$ & rget." & & & & & \\
\hline
\end{tabular}


Table 6: Inflation Expectations and Inflation Experience

\begin{tabular}{|c|c|c|c|c|c|c|c|c|}
\hline & \multicolumn{4}{|c|}{$\underline{\lambda=1.834}$} & \multicolumn{4}{|c|}{$\underline{\lambda=1.433}$} \\
\hline & $(1)$ & $(2)$ & $(3)$ & $(4)$ & $(5)$ & $(6)$ & $(7)$ & $(8)$ \\
\hline Weighted Historical Inflation Rate & $\begin{array}{c}1.304 \\
(0.080)\end{array}$ & $\begin{array}{c}1.304 \\
(0.080)\end{array}$ & $\begin{array}{c}1.252 \\
(0.091)\end{array}$ & $\begin{array}{c}1.022 \\
(0.094)\end{array}$ & $\begin{array}{c}1.058 \\
(0.063)\end{array}$ & $\begin{array}{c}1.057 \\
(0.063)\end{array}$ & $\begin{array}{c}1.024 \\
(0.073)\end{array}$ & $\begin{array}{c}0.837 \\
(0.075)\end{array}$ \\
\hline Household Inflation Rate & & $\begin{array}{c}0.004 \\
(0.008)\end{array}$ & $\begin{array}{c}0.005 \\
(0.008)\end{array}$ & $\begin{array}{c}0.004 \\
(0.009)\end{array}$ & & $\begin{array}{c}0.004 \\
(0.008)\end{array}$ & $\begin{array}{c}0.005 \\
(0.008)\end{array}$ & $\begin{array}{c}0.004 \\
(0.009)\end{array}$ \\
\hline Male & & & $\begin{array}{c}-0.204 \\
(0.100)\end{array}$ & $\begin{array}{c}-0.366 \\
(0.101)\end{array}$ & & & $\begin{array}{c}-0.209 \\
(0.100)\end{array}$ & $\begin{array}{l}-0.369 \\
(0.101)\end{array}$ \\
\hline Married & & & $\begin{array}{c}0.159 \\
(0.087)\end{array}$ & $\begin{array}{c}0.116 \\
(0.086)\end{array}$ & & & $\begin{array}{c}0.145 \\
(0.087)\end{array}$ & $\begin{array}{c}0.105 \\
(0.087)\end{array}$ \\
\hline Constant & $\begin{array}{c}3.399 \\
(0.052)\end{array}$ & $\begin{array}{c}3.401 \\
(0.052)\end{array}$ & $\begin{array}{c}3.477 \\
(0.378)\end{array}$ & $\begin{array}{c}5.106 \\
(0.429)\end{array}$ & $\begin{array}{c}3.315 \\
(0.055)\end{array}$ & $\begin{array}{c}3.317 \\
(0.056)\end{array}$ & $\begin{array}{c}3.407 \\
(0.378)\end{array}$ & $\begin{array}{c}5.049 \\
(0.429)\end{array}$ \\
\hline Occupation Dummies & No & No & Yes & Yes & No & No & Yes & Yes \\
\hline Education Dummies & No & No & Yes & Yes & No & No & Yes & Yes \\
\hline Income Group Dummies & No & No & Yes & Yes & No & No & Yes & Yes \\
\hline Information Dummies & No & No & No & Yes & No & No & No & Yes \\
\hline Observations & 13120 & 13120 & 13120 & 13120 & 13120 & 13120 & 13120 & 13120 \\
\hline$\chi^{2}$ & 268.331 & 268.504 & 366.228 & 614.513 & 277.690 & 277.847 & 375.793 & 622.351 \\
\hline
\end{tabular}

Table 7: Inflation Expectations: CCS and Intage Data

\begin{tabular}{lcccc}
\hline \hline \multirow{2}{*}{ Inflation Range } & Mean & CCS & \multicolumn{2}{c}{ Intage } \\
\cline { 3 - 5 } Std. Dev. & Mean & Std. Dev. \\
\hline$>10 \%$ & 0.055 & 0.228 & 0.09 & 0.287 \\
$5 \%$ to $10 \%$ & 0.254 & 0.435 & 0.278 & 0.448 \\
$2 \%$ to $5 \%$ & 0.447 & 0.497 & 0.298 & 0.457 \\
$0 \%$ to $2 \%$ & 0.128 & 0.334 & 0.087 & 0.282 \\
Approximately $0 \%$ & 0.045 & 0.206 & 0.22 & 0.414 \\
$-2 \%$ to $0 \%$ & 0.018 & 0.133 & 0.012 & 0.108 \\
$-5 \%$ to $-2 \%$ & 0.017 & 0.13 & 0.01 & 0.098 \\
$-10 \%$ to $-5 \%$ & 0.006 & 0.078 & 0.003 & 0.054 \\
$<-10 \%$ & 0.003 & 0.051 & 0.003 & 0.051 \\
\hline \multicolumn{1}{c}{$\mathrm{N}$} & 5674 & \multicolumn{2}{c}{13384} \\
\hline
\end{tabular}

Table 8: Demographic Comparisons

\begin{tabular}{lcccc}
\hline \hline \multirow{2}{*}{ Variable } & \multicolumn{2}{c}{ CCS } & \multicolumn{2}{c}{ Intage Survey } \\
\cline { 2 - 5 } & Mean & Std. Dev. & Mean & Std. Dev. \\
\hline Age & 61.373 & 14.634 & 47.36 & 11.886 \\
Male & 0.782 & 0.413 & 0.518 & 0.5 \\
Household Inc. $<¥ 4 \mathrm{Mil}$ & 0.578 & 0.494 & 0.301 & 0.459 \\
Household Inc. $¥ 4 \mathrm{Mil}-¥ 5.5 \mathrm{Mil}$ & 0.142 & 0.349 & 0.203 & 0.402 \\
Household Inc. $¥ 5.5$ - $¥ 7.5 \mathrm{Mil}(¥ 5.5$ - $¥ 7 \mathrm{Mil})$ & 0.135 & 0.342 & 0.162 & 0.369 \\
Household Inc. $¥ 7.5$ - $¥ 9.5 \mathrm{Mil}(¥ 7$ - $¥ 9 \mathrm{Mil})$ & 0.07 & 0.255 & 0.158 & 0.365 \\
Household Inc. $>¥ 9.5 \mathrm{Mil}(>¥ 9 \mathrm{Mil})$ & 0.075 & 0.263 & 0.174 & 0.379 \\
\hline \multicolumn{2}{c}{$\mathrm{N}$} & \multicolumn{2}{c}{5674} & \multicolumn{3}{c}{13384} \\
\hline
\end{tabular}

Note: Data from the Consumer Confidence Survey and Intage Survey. Numbers in parentheses indicate income range for Intage Survey 
Table 9: Multinomial Logit: Inflation Expectations and Information

\begin{tabular}{|c|c|c|c|}
\hline & $(1)$ & $(2)$ & $(3)$ \\
\hline \multicolumn{4}{|l|}{ Expected Inflation $>10 \%$} \\
\hline \multirow[t]{2}{*}{ Knows About Inflation Target Generally } & 0.077 & 0.137 & 0.643 \\
\hline & $(0.143)$ & $(0.151)$ & $(0.176)$ \\
\hline \multirow[t]{2}{*}{ Has Heard About Target } & 0.386 & 0.517 & 1.196 \\
\hline & $(0.149)$ & $(0.169)$ & $(0.197)$ \\
\hline \multirow[t]{2}{*}{ Has Not Heard About Target } & 0.307 & 0.414 & 1.116 \\
\hline & $(0.174)$ & $(0.198)$ & $(0.227)$ \\
\hline \multicolumn{4}{|l|}{$10 \%>$ Expected Inflation $>5 \%$} \\
\hline \multirow[t]{2}{*}{ Knows About Inflation Target Generally } & 0.585 & 0.579 & 0.640 \\
\hline & $(0.118)$ & $(0.124)$ & $(0.134)$ \\
\hline \multirow[t]{2}{*}{ Has Heard About Target } & 0.837 & 0.892 & 1.048 \\
\hline & $(0.122)$ & $(0.137)$ & $(0.149)$ \\
\hline \multirow[t]{2}{*}{ Has Not Heard About Target } & 0.564 & 0.651 & 0.856 \\
\hline & $(0.142)$ & $(0.159)$ & $(0.174)$ \\
\hline \multicolumn{4}{|l|}{$5 \%>$ Expected Inflation $>2 \%$} \\
\hline \multirow[t]{2}{*}{ Knows About Inflation Target Generally } & 0.501 & 0.430 & 0.437 \\
\hline & $(0.113)$ & $(0.118)$ & $(0.127)$ \\
\hline \multirow[t]{2}{*}{ Has Heard About Target } & 0.673 & 0.603 & 0.622 \\
\hline & $(0.118)$ & $(0.131)$ & $(0.141)$ \\
\hline \multirow[t]{2}{*}{ Has Not Heard About Target } & 0.544 & 0.511 & 0.532 \\
\hline & $(0.137)$ & $(0.153)$ & $(0.166)$ \\
\hline \multicolumn{4}{|l|}{ Expected Inflation $=0$} \\
\hline \multirow[t]{2}{*}{ Knows About Inflation Target Generally } & 0.684 & 0.585 & 0.614 \\
\hline & $(0.131)$ & $(0.136)$ & $(0.149)$ \\
\hline \multirow[t]{2}{*}{ Has Heard About Target } & 1.283 & 1.095 & 1.118 \\
\hline & $(0.134)$ & $(0.148)$ & $(0.163)$ \\
\hline \multirow[t]{2}{*}{ Has Not Heard About Target } & 1.533 & 1.231 & 1.207 \\
\hline & $(0.149)$ & $(0.167)$ & $(0.185)$ \\
\hline $0 \%>$ Expected Inflation $>-2 \%$ & & & \\
\hline Knows About Inflation Target Generally & 0.664 & 0.668 & 1.008 \\
\hline & $(0.374)$ & $(0.382)$ & $(0.403)$ \\
\hline Has Heard About Target & 1.091 & 1.092 & 1.419 \\
\hline & $(0.376)$ & $(0.413)$ & $(0.458)$ \\
\hline Has Not Heard About Target & 1.085 & 1.059 & 1.348 \\
\hline & $(0.403)$ & $(0.449)$ & $(0.498)$ \\
\hline$-2 \%>$ Expected Inflation $>-5 \%$ & & & \\
\hline Knows About Inflation Target Generally & 0.504 & 0.473 & 0.691 \\
\hline & $(0.380)$ & $(0.391)$ & $(0.430)$ \\
\hline Has Heard About Target & 0.899 & 0.827 & 1.052 \\
\hline & $(0.377)$ & $(0.429)$ & $(0.465)$ \\
\hline Has Not Heard About Target & 0.759 & 0.653 & 0.872 \\
\hline & $(0.430)$ & $(0.495)$ & $(0.536)$ \\
\hline$-5 \%>$ Expected Inflation $>-10 \%$ & & & \\
\hline Knows About Inflation Target Generally & 0.960 & 0.926 & 1.052 \\
\hline & $(0.767)$ & $(0.829)$ & $(0.948)$ \\
\hline Has Heard About Target & 1.230 & 1.120 & 1.479 \\
\hline & $(0.783)$ & $(0.874)$ & $(1.001)$ \\
\hline Has Not Heard About Target & 0.793 & 0.714 & 0.858 \\
\hline & $(0.929)$ & $(0.998)$ & $(1.161)$ \\
\hline$-10 \%>$ Expected Inflation & & & \\
\hline Knows About Inflation Target Generally & 0.955 & 1.107 & 1.975 \\
\hline & $(1.100)$ & $(1.092)$ & $(1.002)$ \\
\hline Has Heard About Target & 1.429 & 1.658 & 3.053 \\
\hline & $(1.095)$ & $(1.159)$ & $(1.073)$ \\
\hline Has Not Heard About Target & 3.218 & 3.286 & 4.662 \\
\hline & $(1.080)$ & $(1.174)$ & $(1.101)$ \\
\hline Observations & 13384 & 13384 & 13384 \\
\hline Pseudo $R^{2}$ & 0.020 & 0.024 & 0.032 \\
\hline Standard errors in parentheses. & & & \\
\hline The base category of the dependent variable is & pected inf & tion of $0 \%$ & the BOJ' \\
\hline The base category of the independent variable is & "knows we & about th & \\
\hline rom Intage Sur & & & \\
\hline
\end{tabular}


1-Year Ahead Inflation Expectations

Over Age

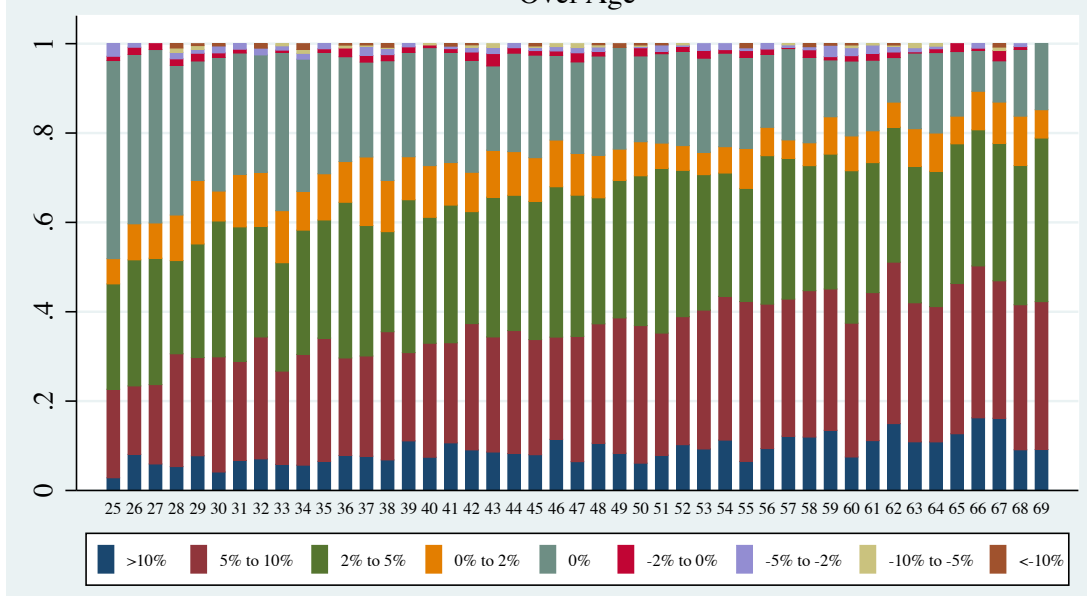

Note: Each color segment represents the proportion of respondents within the given age group that believes their personal inflation rate in the following year will be within the specified range. Data from Intage Survey.

Figure 1: Distribution of Inflation Expectations Over Age 


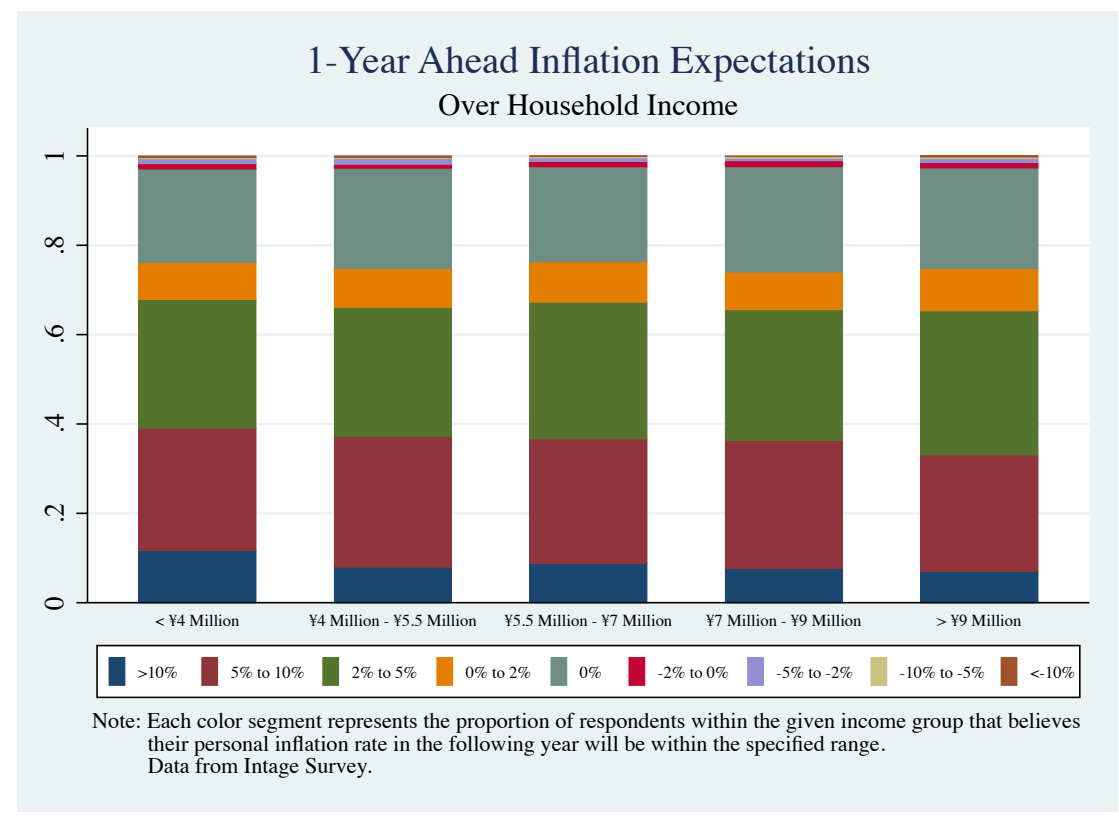

Figure 2: Distribution of Inflation Expectations Over Annual Household Income 


\section{Price Level Across Age Groups (Weighted)}

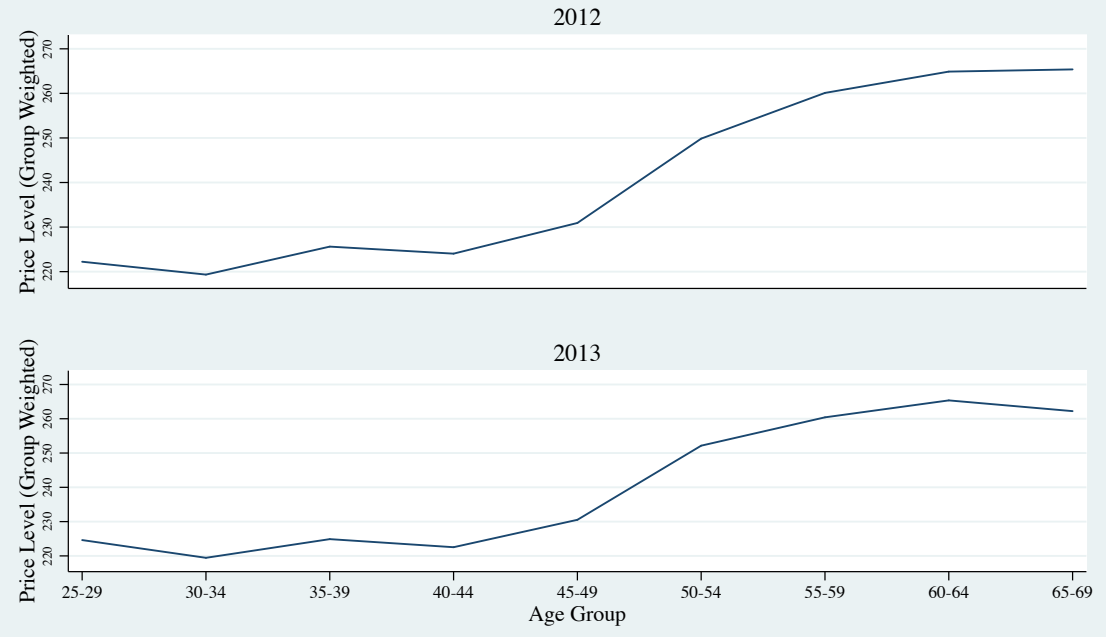

Note: Weighted aggregate price level for each age group using JAN codes with data for all groups in given year. Weights calculated from share of age group's consumption bundle. Weights calculated from shar
Data from Intage Survey.

\section{Price Level Across Age Groups (Unweighted)}
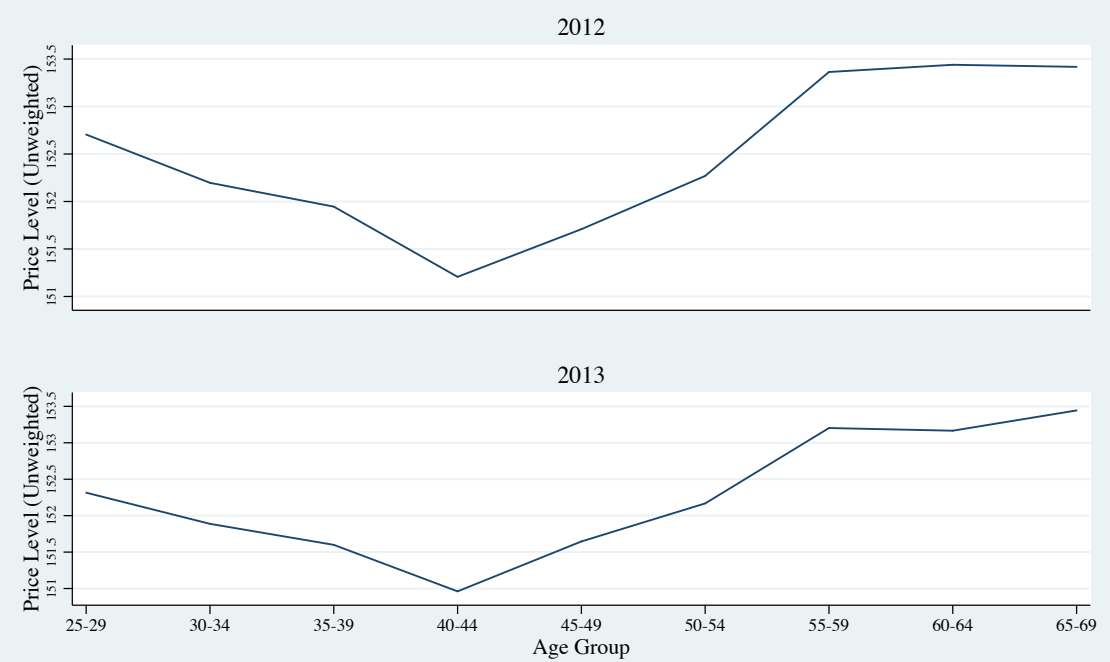

Note: Unweighted aggregate price level for each age group using JAN codes with data for all groups in given year Data from Intage Survey.

Figure 3: Household Consumption Basket Price Level 


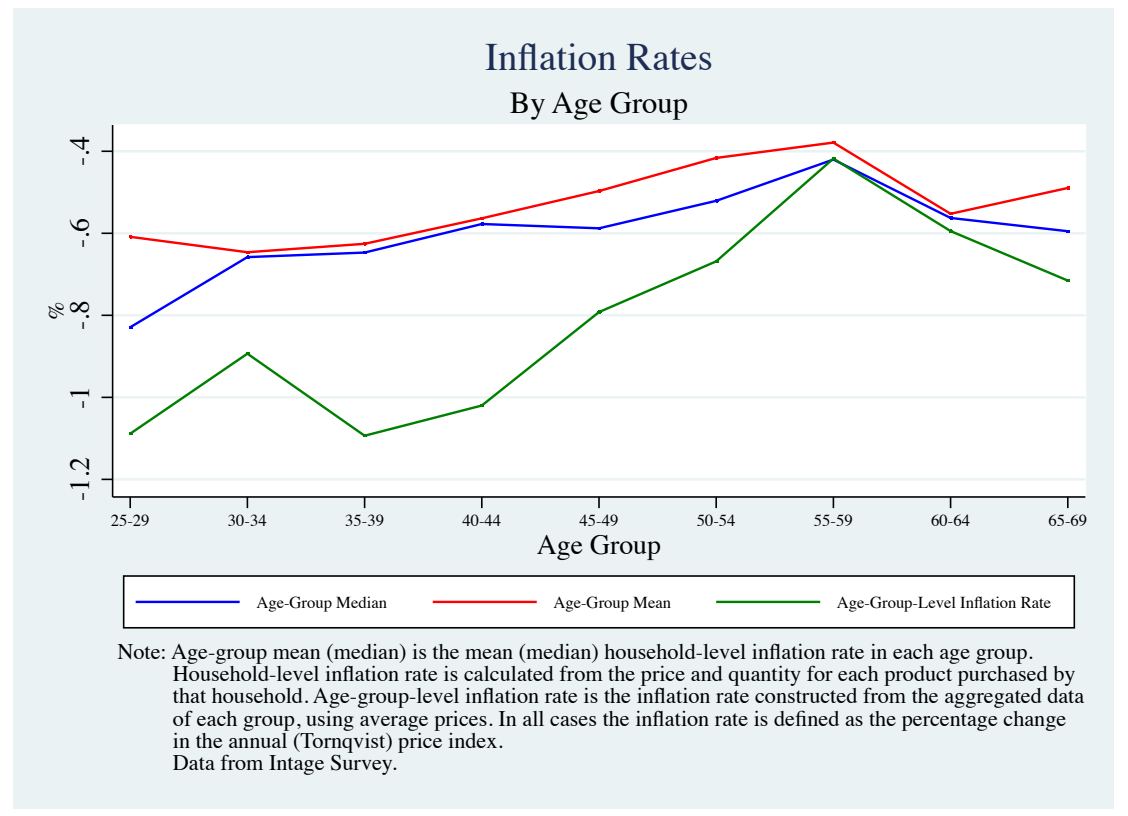

Figure 4: Inflation Rate by Age Group

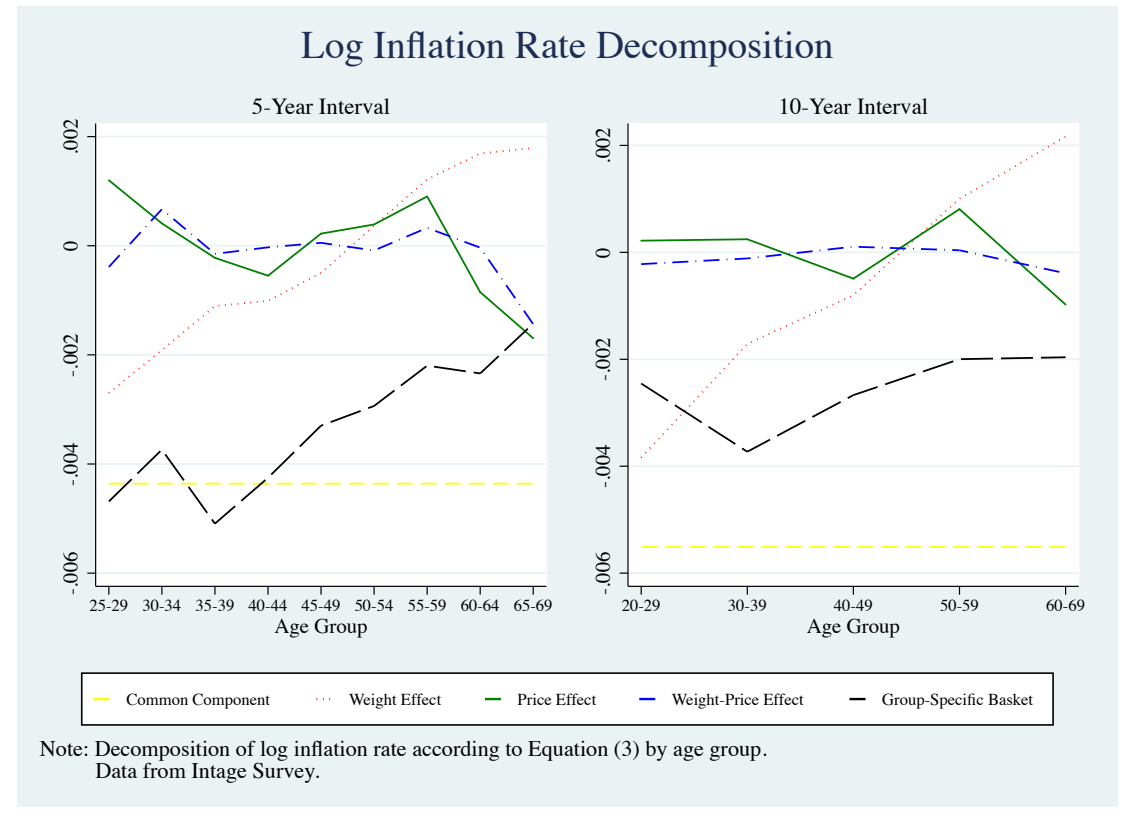

Figure 5: Decomposition of Inflation Rate 


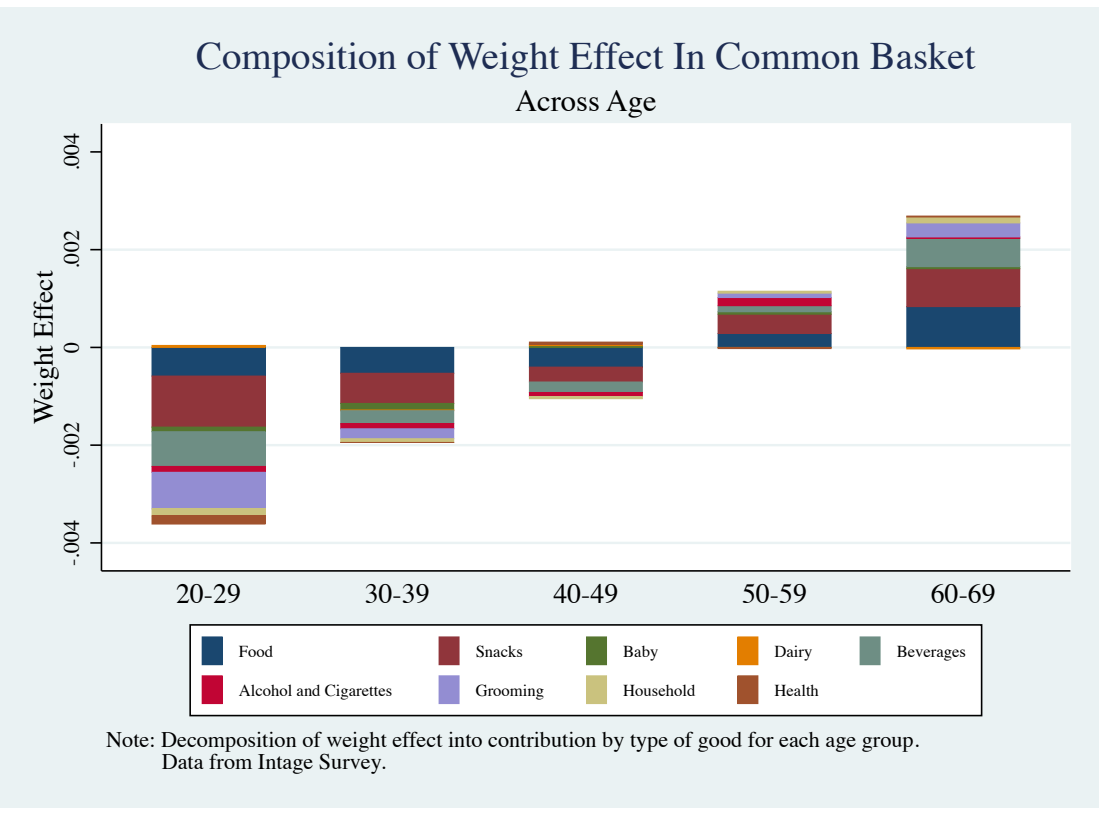

Figure 6: Decomposition of Weight Effect 

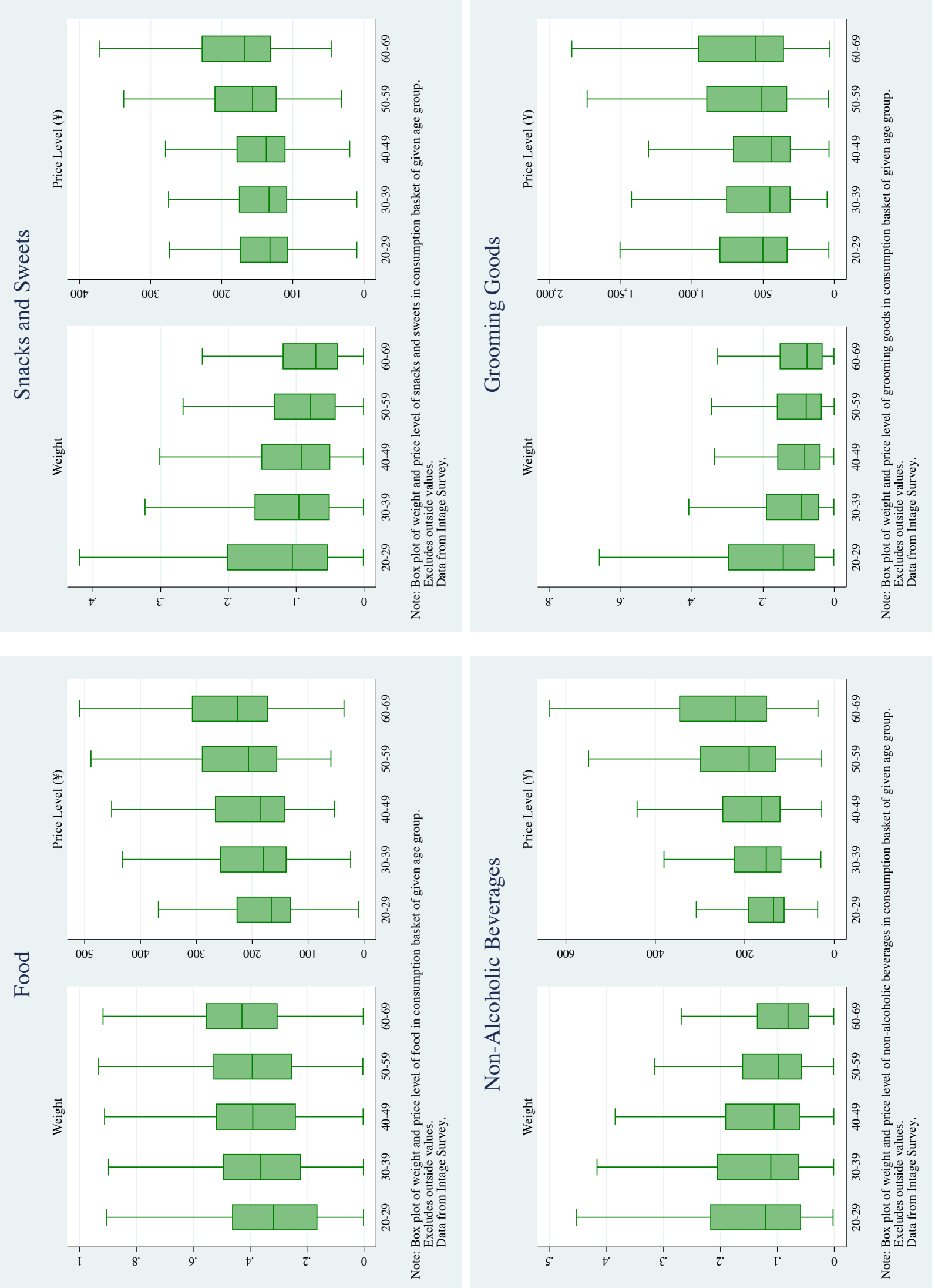

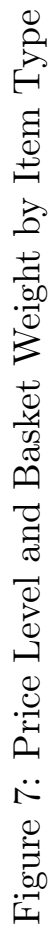




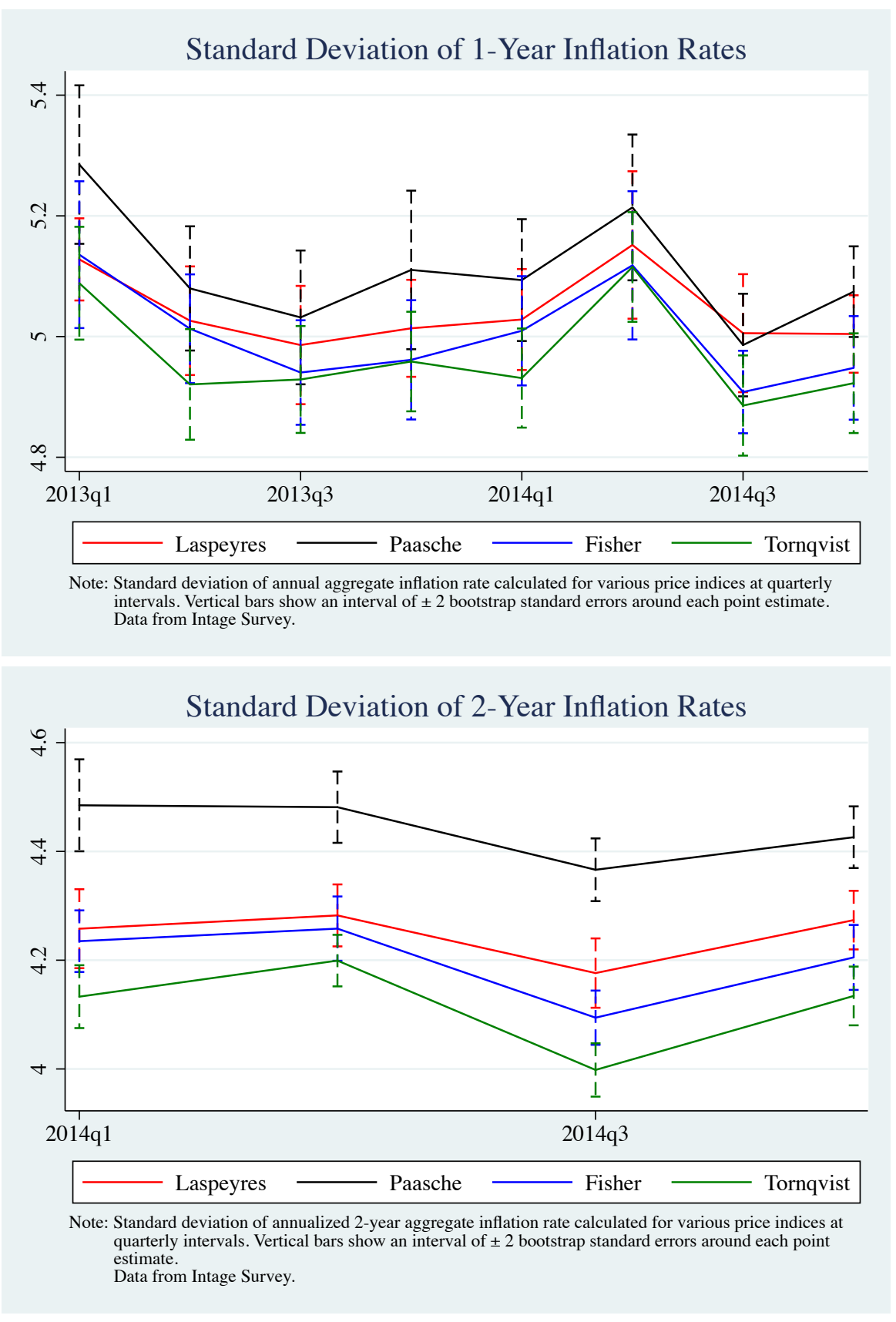

Figure 8: Standard Deviation of Household-Level Inflation Rates 


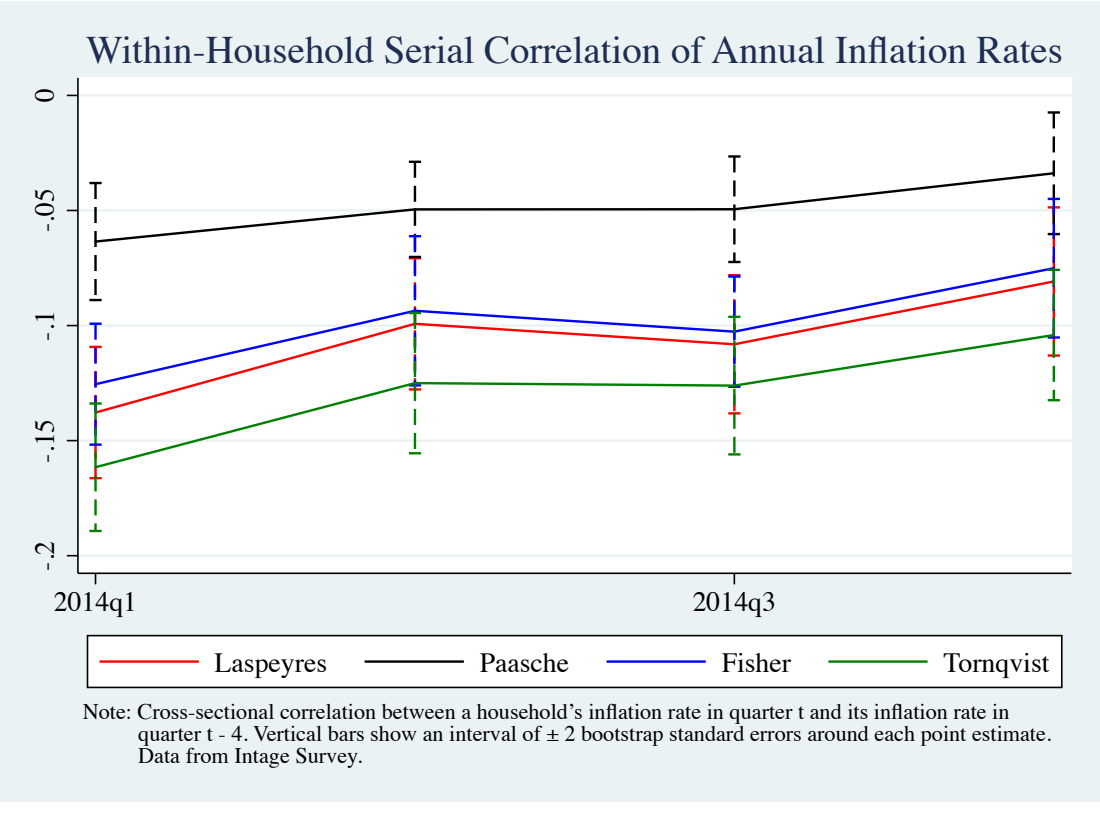

Figure 9: Within-Household Serial Correlation of Annual Inflation Rates

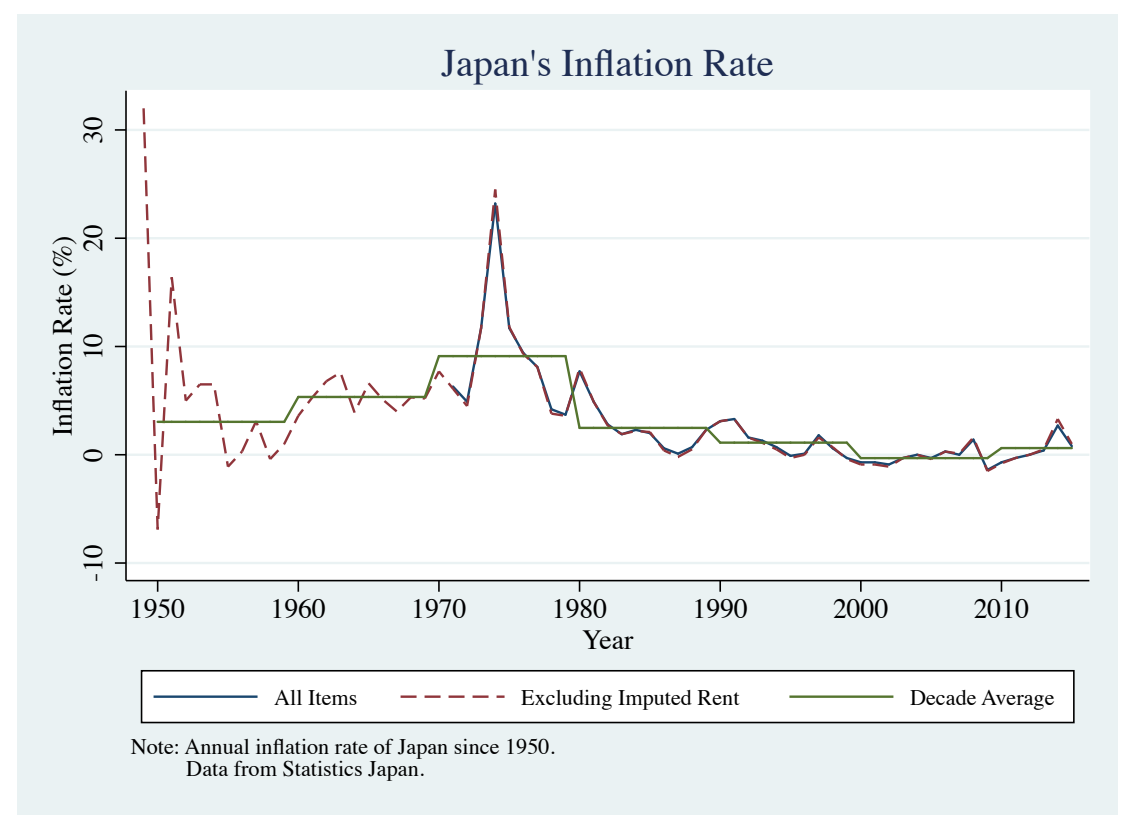

Figure 10: Japan's Inflation History 


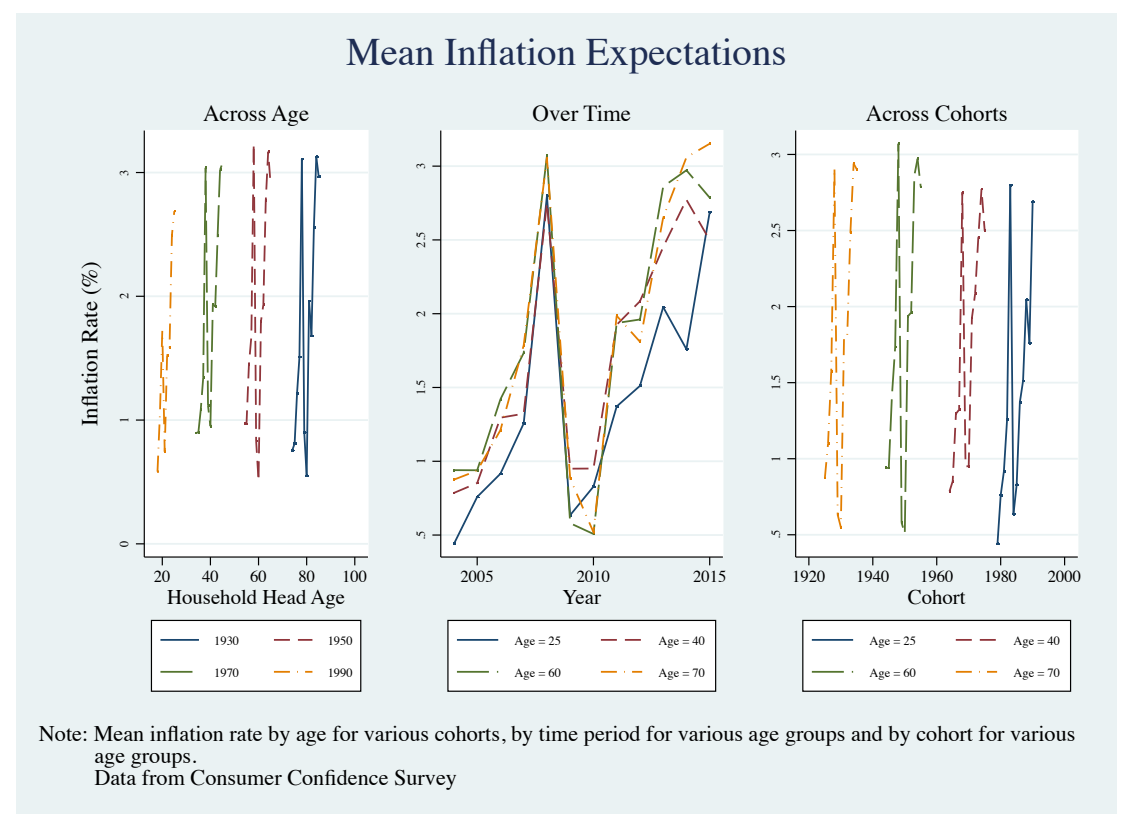

Figure 11: Age, Cohort and Time Effects of Inflation Expectations

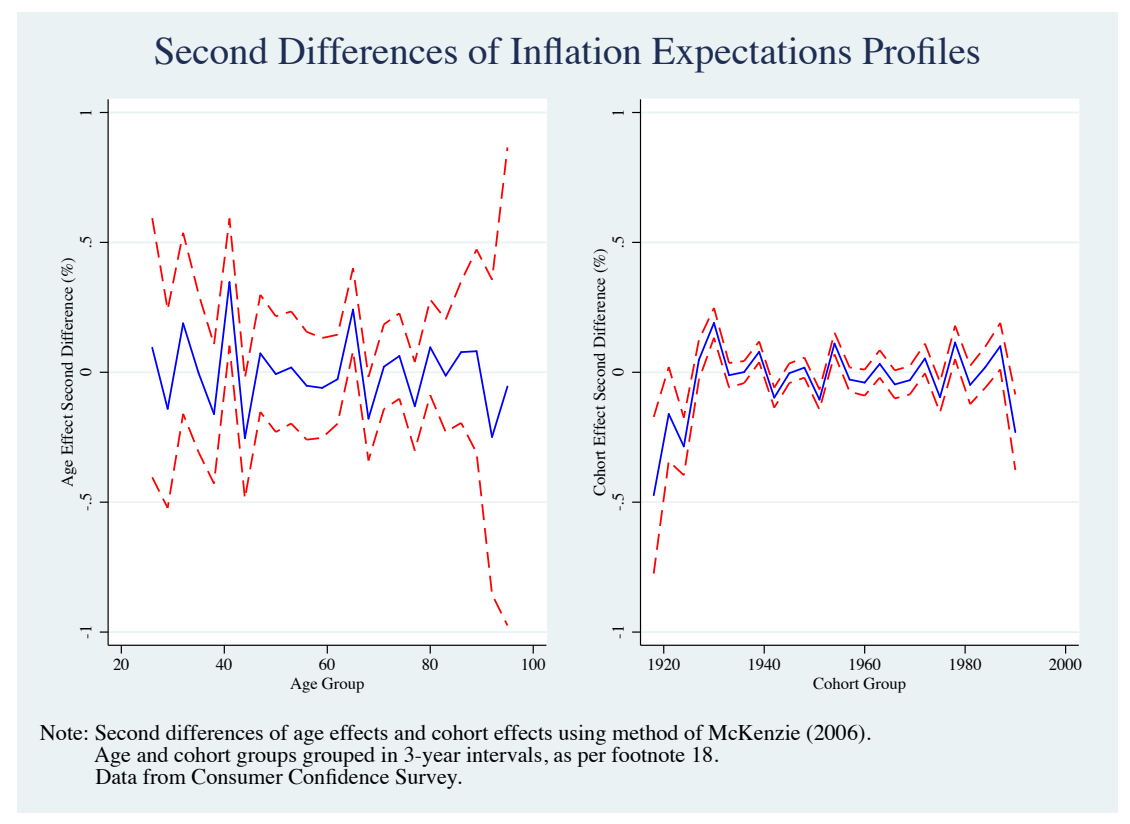

Figure 12: Second Differences of Inflation Expectations Profiles 


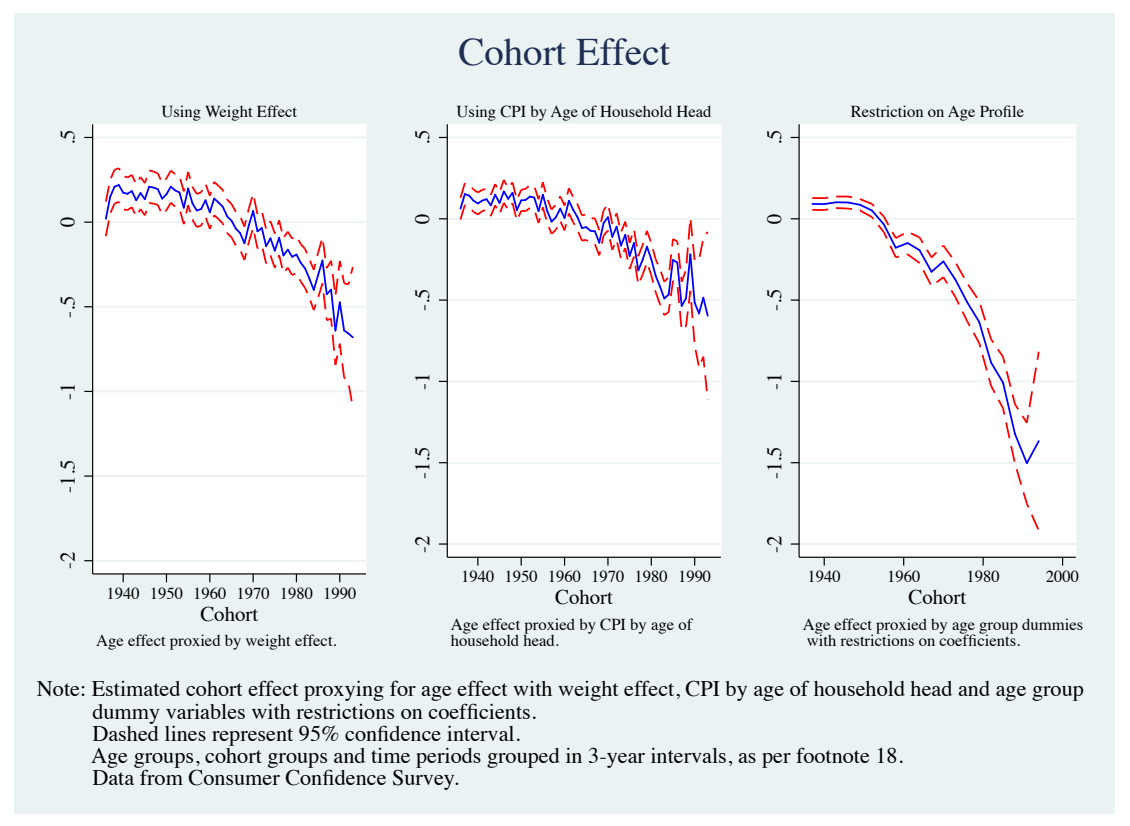

Figure 13: Estimated Cohort Effect

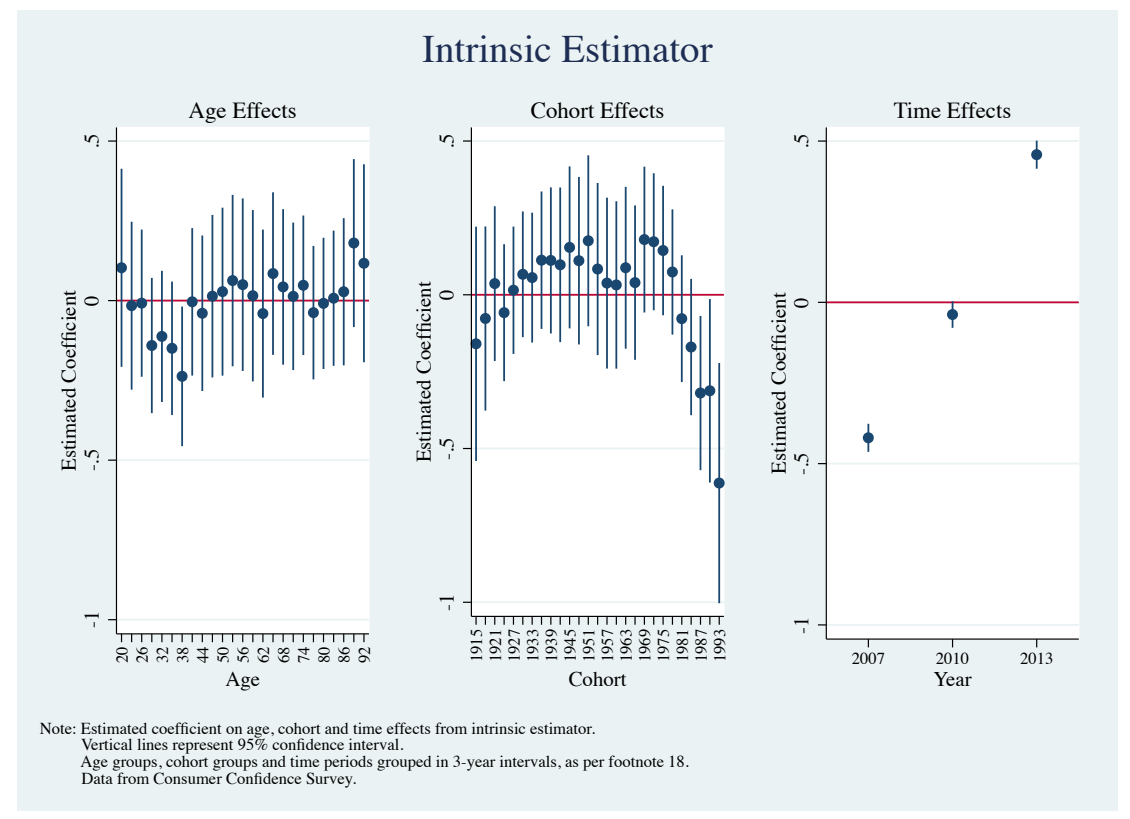

Figure 14: Intrinsic Estimator 

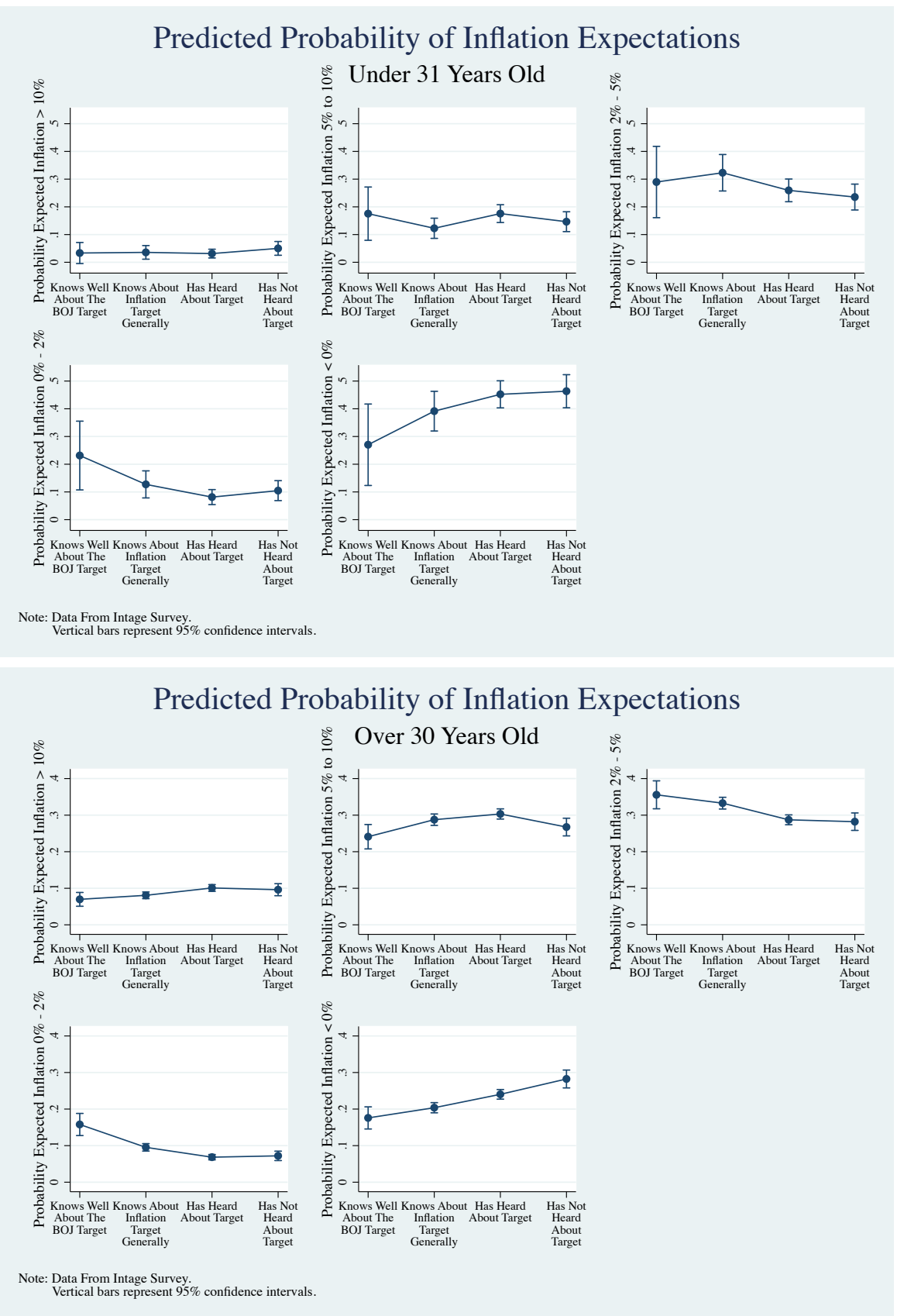

Figure 15: Predicted Inflation Expectation By Knowledge of BOJ's 2\% Target 


\section{Appendix A: Survey Questionnaire}

This appendix provides an English translation of the survey questions.

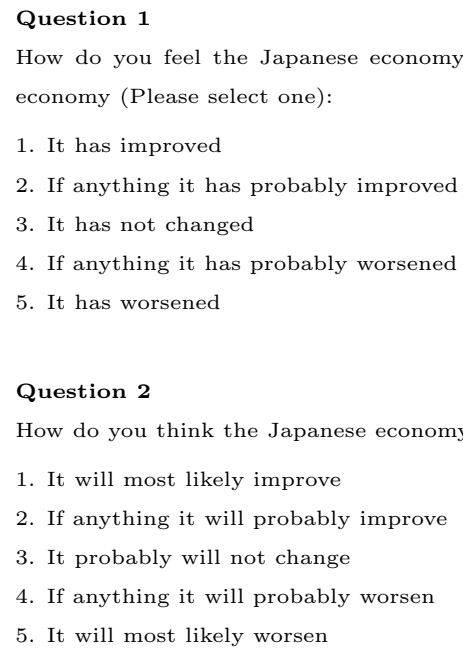
economy (Please select one):

1. It has improved

2. If anything it has probably improved

3. It has not changed

4. If anything it has probably worsened

5. It has worsened

\section{Question 2}

1. It will most likely improve

2. If anything it will probably improve

3. It probably will not change

4. If anything it will probably worsen

5. It will most likely worsen

How do you feel the Japanese economy is performing compared to a year ago? We are asking about the general state of the

How do you think the Japanese economy will be in a year compared to today? (Please select one):

\section{Question 3}

What has happened to your income (salary, etc) compared to a year ago? (Please select one):

1. It has improved

2. If anything it has probably improved

3. It has not changed

4. If anything it has probably worsened

5. It has worsened

\section{Question 4}

What do you think will happen to your income in a year? (Please select one):

1. It will most likely improve

2. If anything it will probably improve

3. It probably will not change

4. If anything it will probably worsen

5. It will most likely worsen

\section{Question 5}

How have "prices" changed compared to a year ago? By "prices" we mean the overall prices of items that you purchase, including food, clothing, daily necessities, household electric appliances, automobiles, eating out, travel, utilities, educational expenses, medical expenses, etc. Please exclude the part of the change in prices that came from the increase in the consumption tax rate last April. We are asking about prices. (Please select one):

1. Prices rose substantially

2. Prices rose slightly

3. Prices hardly changed

4. Prices fell slightly

5. Prices fell substantially

\section{Question 6}

What was the reason for your answering that prices rose, fell or hardly changed? (Please select 3 reasons from the list below in order of relevance): 
1. I reached my judgement based on the prices of items that I purchase daily (e.g. food, daily necessities, clothing, etc).

2. I reached my judgement based on the prices of items that I purchase occasionally (e.g. household electric appliances, automobiles, etc).

3. I reached my judgement based on the cost of eating out (at restaurants, etc).

4. I reached my judgement based on the price of energy (e.g. gasoline, utilities, etc).

5. I reached my judgement based on the cost of rent.

6. I reached my judgement based on the cost of education (e.g. tuition, cram school fees, etc).

7. I reached my judgement based on the cost of transport and communication.

8. I reached my judgement based on medical costs.

9. I reached my judgement based on the prices of something else. In particular:

10. I reached my judgement based on the prices of nothing in particular.

\section{Question 7}

By what percent do you feel the prices have changed compared to a year ago? (Please select one):

1. Prices rose by $10 \%$ or more

2. Prices rose by between $5 \%$ and $10 \%$

3. Prices rose by between $2 \%$ and $5 \%$

4. Prices rose by between $0 \%$ and $2 \%$

5. Prices did not change

6. Prices fell by between $0 \%$ and $2 \%$

7. Prices fell by between $2 \%$ and $5 \%$

8. Prices fell by between $5 \%$ and $10 \%$

9. Prices fell by $10 \%$ or more

\section{Question 8}

Was the change in prices during the last year (from 1 year ago until today) unexpected to you? Or did you expect the change? Please select the option that best describes your feeling. (Please select one):

1. A year ago I expected that prices would rise, but prices actually rose more than I expected.

2. A year ago I expected that prices would rise and prices rose as much as I expected.

3. A year ago I expected that prices would rise. Prices rose, but not by as much as I expected.

4. A year ago I expected that prices would rise, but prices actually did not change.

5. A year ago I expected that prices would rise, but prices actually fell.

6. A year ago I expected that prices would not change and, as expected, prices did not change.

7. A year ago I expected that prices would not change, but prices actually rose.

8. A year ago I expected that prices would not change, but prices actually fell.

9. A year ago I expected that prices would fall, but prices actually fell more than I expected.

10. A year ago I expected that prices would fall and prices fell as much as I expected.

11. A year ago I expected that prices would fall. Prices fell, but not by as much as I expected.

12. A year ago I expected that prices would fall, but prices actually did not change.

13. A year ago I expected that prices would fall, but prices actually rose.

\section{Question 9}

When did you feel prices start to rise? (Please select one):

1. More than 2 years ago

2. Between 1 and 2 years ago

3. 1 year ago

4. Within 1 year (in the last few months)

\section{Question 10}

What do you think will happen to prices in a year compared to today? (Please select one):

1. Prices will probably rise substantially

2. Prices will probably rise slightly

3. Prices will probably hardly change 
4. Prices will probably fall slightly

5. Prices will probably fall substantially

\section{Question 11}

What was the reason for your answering that prices will probably rise, fall or hardly change in the next year in question 10 ? (Please select 5 reasons from the list below in order of relevance):

1. I reached my judgement based on what I expect to happen to the prices of items that I purchase daily (e.g. food, daily necessities, clothing, etc).

2. I reached my judgement based on what I expect to happen to the prices of items that I purchase occasionally (e.g. household electric appliances, automobiles, etc).

3. I reached my judgement based on what I expect to happen to the cost of eating out (at restaurants, etc).

4. I reached my judgement based on what I expect to happen to the price of energy (e.g. gasoline, utilities, etc).

5. I reached my judgement based on what I expect to happen to the prices of transport and communication, medical expenses, rent and the cost of education.

6. I reached my judgement based on what I heard from mass communication such as newspapers, magazines and television.

7. I reached my judgement based on what I read on the internet.

8. I reached my judgement based on what I heard from experts (economists) at a brokerage firm.

9. I reached my judgement based on the exchange rate (weakening or strengthening of the yen).

10. I reached my judgement based on stock prices.

11. I reached my judgement based on the prices of houses and land.

12. I reached my judgement based on the prices of goods that I deal with at work.

13. I reached my judgement based on conversations with friends, family or colleagues.

14. I reached my judgement based on my income (salary) or the incomes (salaries) of people around me.

15. I reached my judgement based on the policies of the government and the Bank of Japan.

16. I reached my judgement based on some other reason. In particular:

17. I reached my judgement based on nothing in particular.

\section{Question 12}

By what percent do you think prices will change in the next year compared to today? Please do not include the rise in the consumption tax rate that is expected to be introduced this April. (Please select one):

1. Prices will probably rise by $10 \%$ or more

2. Prices will probably rise by between $5 \%$ and $10 \%$

3. Prices will probably rise by between $2 \%$ and $5 \%$

4. Prices will probably rise by between $0 \%$ and $2 \%$

5. Prices will probably not change

6. Prices will probably fall by between $0 \%$ and $2 \%$

7. Prices will probably fall by between $2 \%$ and $5 \%$

8. Prices will probably fall by between $5 \%$ and $10 \%$

9. Prices will probably fall by $10 \%$ or more

\section{Question 13}

Do you know about the economic policies of the Abe administration (Abenomics)? We are asking about Abenomics. (Please select one):

1. I know a lot about it.

2. I know about it generally.

3. I have heard about it, but I do not know about it in detail.

4. I have never heard about it.

\section{Question 14}

Do you think that Abenomics is effective in helping the economy recover? (Please select one):

1. I think that it is effective.

2. I do not think that it is effective.

3. I do not know. 


\section{Question 15}

The yen has weakened under Abenomics. Is this a good thing or a bad thing? (Please select one):

1. A weakening of the yen is a good thing because it has increased exports and boosted the profits of exporters.

2. A weakening of the yen is a good thing. However, the reason is not that exports increase.

3. A weakening of the yen a bad thing. It causes the prices of imports to rise.

4. A weakening of the yen a bad thing. A fall in the value of the yen is due to a loss of national prosperity.

5. A weakening of the yen a bad thing. However, the reason has nothing to do with the price of imports or national prosperity.

6. Other. In particular:

\section{Question 16}

Are you actively interested in the economy? (Please select one):

1. I am interested in the economy and eagerly read newspapers, magazines, the internet or watch television everyday.

2. I do not have a particularly deep interest in the economy, but I do check newspapers, magazines, the internet or television daily.

3. I check newspapers, magazines, the internet or television when I need to for work.

4. I check newspapers, magazines, the internet or television when I have spare time.

5. I have absolutely no interest in the economy.

\section{Question 17}

Are you interested in the Consumer Price Index, published by the Ministry of Internal Affairs and Communications Statistics Bureau? (Please select one):

1. I am interested in the Consumer Price Index and check the newspaper or television.

2. I know what the Consumer Price Index is and sometimes check the newspaper or television.

3. I know what the Consumer Price Index is, but I am not very interested in it.

4. I do not know what the Consumer Price Index is.

\section{Question 18}

By what percent have consumer prices risen since the beginning of the year (compared to the same period last year, how much have consumer prices risen)? Please answer with a number. Please answer using only your memory and without checking the internet or any other source.

\section{Question 19}

The government and the Bank of Japan believe that deflation, in which prices fall, is undesirable. In April of last year they began a policy that aims to raise prices by $2 \%$ a year. Do you know about this policy? (Please select one):

1. I know a lot about it.

2. I know about it generally.

3. I have heard about it, but I do not know about it in detail.

4. I have never heard about it.

\section{Question 20}

Do you think that a policy of raising prices by $2 \%$ a year is desirable? (Please select one)

1. It is extremely desirable.

2. It is desirable.

3. It is somewhat desirable.

4. It is undesirable.

\section{Question 21}

Why do you think that a policy of raising prices by $2 \%$ a year is desirable? (Please select 2 reasons from the list below in order of relevance):

1. Because my income (salary, etc) will rise.

2. Because the economy will improve.

3. Because the yen will weaken.

4. Because it would be bad for deflation to continue.

5. Other reason. In particular: 
6. No reason in particular.

\section{Question 22}

Why do you think that a policy of raising prices by $2 \%$ a year is undesirable? (Please select 2 reasons from the list below in order of relevance):

1. Because the prices of goods and services will rise.

2. Because the yen will weaken.

3. Because I think that it would be better for prices to rise by more than $2 \%$.

4. Because I think that it would be better for prices to rise by less than $2 \%$.

5. Because I think that it would be good for deflation to continue.

6. Other reason. In particular:

7. No reason in particular.

\section{Question 23}

Do you think that the policy of aiming to raise prices by $2 \%$ a year will succeed? (Please select one):

1. I think that it will certainly succeed.

2. I think that there is a high probability that it will succeed.

3. While not zero, I think that the probability that it will succeed is low.

4. I think that it will fail.

5. I do not know.

\section{Question 24}

The Japanese government is issuing a large amount of government bonds and public finances are in a difficult situation. What do you think about this? (Please select one)

1. I think that there is a need to solve the public finance problem because it is serious. Taxes must be raised (e.g. raising the consumption tax rate).

2. I think that the public finance problem is important, but dealing with the issue by reducing government spending, not by raising taxes, is the logical approach.

3. The public finance problem is not very serious. There are more important issues, such as the state of the economy and employment.

4. Other. In particular:

5. I am not sure.

\section{Question 25}

Do you currently have a home loan? We are asking about you yourself. (Please select one):

1. I have a loan

2. I do not have a loan.

\section{Question 26}

Is the interest rate on your home loan fixed or variable? (Please select one):

1. It is currently variable and I do not plan to change it.

2. It is currently fixed and I do not plan to change it.

3. I changed it from variable to fixed some time ago (within the last year) or I am planning to change it from variable to fixed.

4. I changed it from fixed to variable some time ago (within the last year) or I am planning to change it from fixed to variable.

5. Other. In particular:

\section{Question 27}

Have you recently purchased real estate (a house and land) or are you planning on purchasing real estate? (Please select one):

1. I purchased real estate some time ago (within the last year).

2. I would like to purchase real estate as soon as possible.

3. I am thinking about purchasing real estate, but the time is not right yet.

4. I am not thinking about purchasing real estate. 


\section{Question 28}

Have you recently purchased (or traded-in) an automobile or are you planning on purchasing (or trading-in) an automobile? (Please select one):

1. I purchased (or traded-in) an automobile some time ago (within the last year).

2. I would like to purchase (or trade-in) an automobile as soon as possible.

3. I am thinking about purchasing (or trading-in) an automobile, but the time is not right yet.

4. I am not thinking about purchasing (or trading-in) an automobile.

\section{Question 29}

Have you recently purchased (or traded-in) household electronic appliances (such as a television, refrigerator, washing machine, computer, etc) or are you planning on purchasing (or trading-in) household electronic appliances? (Please select one):

1. I purchased (or traded-in) household electronic appliances some time ago (within the last year).

2. I would like to purchase (or trade-in) household electronic appliances as soon as possible.

3. I am thinking about purchasing (or trading-in) household electronic appliances, but the time is not right yet.

4. I am not thinking about purchasing (or trading-in) household electronic appliances.

\section{Question 30}

Have you recently reduced the amount of cash and bonds and increased the amount of stocks (or stock-based mutual funds) that you hold or are you planning on doing so? (Please select one):

1. I have recently (within the last year) reduced my cash and bonds and increased the amount of stocks that I hold.

2. I would like to increase the amount of stocks that I hold as quickly as possible.

3. I have actually reduced the amount of stocks that I hold or am planning on reducing the amount of stocks that I hold.

4. I have not changed the ratio of cash, bonds and stocks that I hold, nor do I plan on doing so.

\section{Question 31}

Have you recently increased the amount of foreign currency assets (for example, stocks, bonds or mutual funds that are sold in U.S. dollars or other foreign currencies) that you hold or are you planning on doing so? (Please select one):

1. I have recently (within the last year) increased the amount of foreign currency assets that I hold.

2. I would like to increase the amount of foreign currency assets that I hold as quickly as possible.

3. I have actually reduced the amount of foreign currency assets that I hold or am planning on reducing the amount of foreign currency assets that I hold.

4. I have not changed the ratio of foreign currency assets that I hold, nor do I plan on doing so.

\section{Question 32}

Do you vote in elections? (Please select one):

1. I always vote.

2. I sometimes vote.

3. I do not vote much.

4. I never vote.

5. I am not eligible to vote.

\section{Question 33}

Which of the following do you consider to be important when you vote? (Please select 3 options from the list below in order of importance):

1. Deflation

2. Public finances and taxes

3. Employment and inequality

4. Low birth rate, aging of society and childcare support

5. Education

6. Healthcare and welfare

7. Foreign relations

8. The environment and resources

9. Other. In particular:

10. Nothing in particular 